\title{
Aproximación sistemática a la ética cristiana de la violencia revolucionaria
}

\section{PLANTEAMIENTO DEL PROBLEMA Y CONSIDERACIONES PRELIMINARES}

Pretendo en esta primera parte delimitar la realidad sobre la cual voy a hacer el juicio moral y presentar las principales dificultades que ofrece esta realidad a la conciencia creyente.

El problema ético de la revolución lo formula $\mathrm{H}$. Marcuse con el siguiente interrogante: ¿se puede justificar el recurso de la violencia como mediación para promover y establecer la libertad y dicha humanas? '.

La problematicidad ética y política de la violencia estriba en su ambigüedad. Éticamente el creyende se enfrenta con el hecho de que la violencia, con la que pretende construir un ordenamiento socio-político más justo y humano, desmantela valores al parecer tan absolutos e inalienables como la vida y la libertad humanas, aparte de que no parece compaginable por su función objetiva con el espítiru evangélico de las bienaventuranzas y con el mandamiento del amor. Políticamente su ambigüedad estriba en la complejidad que rodea al discernimiento de su oportunidad coyuntural o estratégica, tanto por lo que respecta a su puesta en marcha como por lo que se refiere a su efectividad o consecución de los objetivos de libertad y de justicia propuestos: ninguna revolución está asegurada, por inevitables imposiciones coyunturales, del riesgo de engendrar nuevas injusticias. Una revolución triunfante puede resultar tan inhumana como el orden injusto derrocado, y en este sentido resultarían ética y socio-políticamente inútiles, y por tanto inmorales, los «costos» humanos y sociales que la violencia revolucionaria acarreó.

Por ello conviene comenzar con una importante clarificación: las reflexiones y análisis de este trabajo versan sobre la eticidad de una forma concreta de la violencia: la violencia revolucionaria que intenta responder a una previa

1. Cfr. H. Marcuse, Ética de la revolución, (Madrid 1970), p. 143. 
«violencia institucionalizada» en un ordenamiento socio-político injusto dentro del marco de una revolución que por hipótesis persigue la implantación de un ordenamiento sociopolítico más justo. Parto, pues, del supuesto de que no debe plantear ningún problema de discernimiento ético tanto la cuestión de la «violencia establecida» en base a un ordenamiento socio-político injusto, como la de una "violencia revolucionaria» a la que se recurriese para la implantación de un ordenamiento socio-político más inhumano aún que el previamente «establecido».

El cuadro de las posibles hipótesis que hay que tener en cuenta puede formularse de la forma siguiente:

- posibilidad de arribar a una revolución de estructuras por medio de las técnicas y presiones de la no-violencia activa e inviabilidad de la violencia revolucionaria armada para llegar a dicha revolución de estructuras, que están implantadas en un ordenamiento socio-político injusto.

- la hipótesis contraria: posibilidad de llegar a la revolución de unas estructuras establecidas injustamente únicamente por medio de la violencia revolucionaria armada, al resultar inviables para tạl finalidad las técnicas de la noviolencia activa.

- viabilidad tanto de la no-violencia activa como de la violencia revolucionaria armada para alcanzar la revolución estructural.

-imposibilidad, en una situación determinada, de la revolución de unas estructuras injustas por resultar inviables tanto la no-violencia activa como la violencia revolucionaria armada.

El discernimiento sobre las posibilidades e imposibilidades que realmente existan en una situación determinada está mediatizado por los análisis y cálculos científicos, pero no de una forma exclusiva, ya que nunca podrán desbancarse por completo la apuesta, la conjetura, la intuición y el riesgo, dado que la complejidad de las decisiones de tipo político nunca queda completamente acotada por los datos y factores científicamente compulsables. Todo proyecto revolucionario, con la consiguiente decisión por la violencia armada o por las técnicas no-violentas, conlleva un componente de riesgo, de apuesta y de conjetura que no puede ser completamente eliminado por el elemento científico que también implica.

Existe, por tanto, la posibilidad o hipótesis de que en función de la justicia y de la libertad se imponga en una situación determinada la necesidad impostergable de una revolución estructural y el recurso a la violencia armada como mediación suya. Ni desde la ciencia, ni desde la filosofía, ni desde la moral puede descartarse apriorísticamente el hecho de la violencia revolucionaria armada. $\mathrm{Y}$ cuando en una situación de «violencia estructural» su supresión implica una revolución, y en esta situación concreta ésta sólo puede ser mediatizada por vía violenta, es entonces cuando se plantea la cuestión de su discernimiento ético.

La reflexión ética sobre la violencia no debe limitarse a sus propios presupuestos, sino que también ha de tener en cuenta los elementos de juicio proce- 
dentes de otras fuentes de discernimiento. En particular, la psicología puede clarificar hasta qué punto se da un componente de agresividad, instintiva o elaborada, que colorea y modela el encuentro interhumano, y en qué medida los instintos, instancias y estructuras del ser humano pueden ser moldeados para articular una convivencia socio-política más armoniosa. La historia puede constatar cuál ha sido exactamente la presencia y funcionalidad de lo violento en los hitos socio-históricos decisivos, en los grandes virajes del rumbo de la historia. Las ciencias socio-biológicas tienen también su palabra acerca de la presencia y magnitud de la lucha por la existencia en la raza humana, y de qué forma podría ser sublimada a una esfera de competitividad en la que no se dé la agresión mortal entre los hombres.

El ideal ético irrenunciable es la proscripción absoluta de lo violento en la sociabilidad humana. Ésta es la razón de que la no-violencia constituya un imperativo que apunta a una meta hacia la que debe tender toda la humanidad. Pero el nudo del problema estriba en que hoy por hoy la violencia impera y opera con gran extensión e intensidad, y que no hay más remedio que enfrentarse con ella, en ocasiones precisamente sin otra alternativa que el recurso a la misma violencia.

Condenar hoy sin más toda violencia «venga de donde venga» y hacer de esta universal reprobación un criterio práctico indiscriminado resultaría de una ambigüedad y tosquedad ética tan acríticas como si antaño se hubiera condenado todo tipo de violencia bélica o de defensa personal sin discernir entre la parte agresora y la agredida. Por ello la labor de clarificación ética y socio-política sobre el problema que me he propuesto en este trabajo.

Una inicial reserva y suspicacia frente a todo recurso a la violencia resultan imprescindibles para desbancar desde el principio un laxismo que sería totalmente contraproducente en un asunto ética y socio-políticamente tan ambiguo y resbaladizo como el de la violencia. Por ello siempre que el tercer camino que supone la no-violencia (entre la violencia opresivo-represiva institucionalizada y la violencia liberadora) resulte viable y eficaz, de acuerdo con las características específicas de la situación concreta, debe optarse por él. Constituye, pues, un deber ético agotar todos los medios revolucionarios noviolentos, a pesar de los sacrificios y renuncias que supongan. Pero puede suceder que terminen por estrellarse con la resistencia represiva violenta de los poderes establecidos injustos. Si esta represión es de una magnitud masiva queda siempre para el no-violento el interrogante de si le es lícito dejar que dichos poderes ejerzan la represión sobre su prójimo, por no intentar impedirlo con otros medios, en este caso los violentos, si es que en aquella situación resultan los verdaderamente viables y eficaces. Ésta es la razón por la que la violencia revolucionaria puede constituirse en una eventual existencia del amor y de la solidaridad con los oprimidos ${ }^{2}$.

2. Cfr. R. Muñoz, Nueva conciencia de la Iglesia en América Latina, (Salamanca 1974), pp. 201-2. 
El abanico de las posibles calificaciones éticas sobre las tipologías de la violencia se alarga en una amplia gama. El recurso a la violencia aparece tanto más inexcusable e ilegítimo en la medida en que no se necesite realmente de ella porque se dispone de otros medios para conseguir los mismos fines. Adquiere también particular inmoralidad cuando se ejercita sobre seres indefensos o ajenos a la contienda en curso. La violencia del débil no puede ser tachada con la misma gravedad que la del poderoso, quien sin necesitarla para asegurar su dominio, la emplea gratuitamente en un acto más de abuso de su fuerzà y poder. La violencia revolucionaria, cuando se desliza hacia el terrorismo estricto, entraña también un abuso agravante, sobre todo si atenta contra personas indefensas e inocentes.

Si la violencia gratuitamente represiva no puede reclamar prerrogativas o justificaciones éticas, tampoco la violencia revolucionaria queda legitimada o disculpada sin más simplemente porque quiere mediar en el establecimiento de un orden socio-político distinto. La posible justificación de la violencia no procede de un preferente derecho de lo ya instituido en un caso ni de lo aún por crear en el otro, sino del sistema de valores en el que se enmarca, ya sea éste actual o futuro. Ni el mero hecho de conservar ni tampoco el de trastocar poseen por sí mismos derecho a recurrir a la violencia, sino que todo depende de los contenidos concretos que se quieren conservar o proyectar. La violencia que se propone defender los intereses de los sectores opresivos dominantes es radicalmente distinta éticamente de la que se dirige a implantar o salvarguardar los valores relativos al proyecto de una sociedad más justa, libre y fraterna.

La crueldad en el ejercicio de la violencia, sea ésta del tipo que sea, es un componente que la constituye en radicalmente perversa. Nada puede excusar o atenuar la violencia realizada con ensañamiento, refinamiento y odio, y en este contexto merece particular condena todo tipo de tortura.

La violencia ejercida de forma directa sobre las personas humanas reviste un carácter que la diferencia notablemente de la que se verifica sobre las cosas. Los perjuicios materiales producidos sobre las cosas son cualitativamente distintos a los sufrimientos humanos, y particularmente a la pérdida de la vida humana ${ }^{3}$.

La violencia tiene, pues, una tipología que obliga al discernimiento a la hora de su enjuiciamiento ético. La condena indiscriminada de toda violencia puede expresar un noble ideal y anunciar un horizonte de esperanza para la humanidad, pero se sitúa al margen de la urgencia y peculiaridad de los problemas y situaciones concretos planteados en la actualidad. La violencia del que agrede no puede identificarse con la del que defiende. La violencia vindicativa, gratuita y cruel, es particularmente distinta a la que pretende mediar en la implantación de la libertad y de la justicia. La que instaura y man-

3. Cfr. A. Fierro, La fe contra el sistema, (Estella 1972), pp. 233-7. 
tiene un sistema de opresión y de represión no es comparable a la que intenta desmantelarlo para establecer otro distinto. Tampoco se puede colocar a idéntico nivel la violencia que se ejerce sobre las vidas humanas y la que se limita a las cosas. Pero particularmente resulta inmoral en cualquier hipótesis la tortura.

\section{LA JUSTIFICACIÓN HISTÓRICA Y SOCIO-POLÍTICA DE LA VIOLENCIA REVO- LUCIONARIA}

En este segundo apartado pretendo tratar del presupuesto imprescindible para que pueda discutirse la validez ética de la violencia revolucionaria. Antes del juicio ético se requiere la justificación histórica y socio-política de la violencia revolucionaria. Esta necesidad histórica y socio-política es presupuesto de toda posible aceptación ética de la violencia revolucionaria.

La justificación y legitimación histórica y sociopolítica de la violencia revolucionaria se refiere a la verificación de su oportunidad y posibilidad sociohistóricas. Éstas a su vez implican tanto la comprobación y compulsación científicas de las condiciones objetivas de la revolución, cuanto la apuesta seria sobre una probabilidad máxima de que la revolución cumplirá su función objetiva ${ }^{4}$. A este nivel la violencia revolucionaria se presenta como una opción técnica estratégico-táctica, cuyo discernimiento depende, no tanto del juicio ético, cuanto del juicio político. Pero no debe olvidarse que la racionalidad política interviene forzosamente en las concreciones éticas, y de esta forma una violencia revolucionaria políticamente irracional, también lo será éticamente, y por lo tanto inmoral ${ }^{5}$.

La justificación política de la violencia revolucionaria compete a los análisis sobre las condiciones objetivas de la realidad social, sobre los recursos y posibilidades disponibles y sobre los cálculos acerca de la «economía de la violencia». En la línea de las condiciones objetivas hay que compulsar el potencial represivo de que dispone el «sistema establecido», la cualificación de su injusticia y violencia institucionalizadas, el grado de concientización y de preparación de las masas, el tipo y magnitud de las barreras que habrá que solventar, los recursos disponibles para la implantación por vía violenta del

4. Cfr. M. Useros, Cristianos en la vida política, (Salamanca 1971), pp. 200-1.

5. Conviene recordar aquí los tres niveles que para H. Assmann debe asumir la reflexión ético-teológica acerca de una cuestión socio-política:

-nivel de análisis social (instrumental analítico-dialéctico-estructural)

-nivel de opciones políticas (el análisis social no canaliza unilateralmente la opción política; se hace imprescindible la mediación ético-política, ya que la necesaria iluminación no proviene únicamente del análisis social)

-nivel estratégico-táctico. (Cfr. Conciencia cristiana y situaciones extremas en el cambio social, en AA. VV.: «Fe cristiana y cambio social en América Latina», (Salamanca 1973), p. 343. 
nuevo ordenamiento socio-político. En la línea de la función objetiva de la violencia revolucionaria hay que verificar sus posibilidades efectivas y la garantía de que el ordenamiento socio-político parido por la revolución resultará mejor que el injustamente «establecido» que se pretende trastocar. Todos estos componentes analíticos que concurren en el cálculo socio-histórico acerca de la oportunidad y posibilidad socio-políticas de la violencia revolucionaria constituyen el elemento indispensable para que cualquier consideración acerca de su legitimidad ética no degenere en el abstraccionismo estéril.

No sólo éticamente, sino también políticamente, el problema de la justificación del recurso a la violencia revolucionaria se plantea respecto a su carácter de mediación para la promoción y la implantación de la libertad, la justicia y la dicha humanas. Aquí subyace el supuesto de que se dan criterios racionales para determinar los recursos y posibilidades de libertad, de justicia y de dicha a disposición de una comunidad humana en una situación y momento socio-históricos específicos. Por ello todo movimiento revolucionario, para poder recabar derechos éticos, tiene que aportar estos criterios racionales que concreten las posibilidades reales de su oferta de libertad y justicia y la oportunidad y adecuación de sus medios para lograr estos fines. No toda violencia revolucionaria ha tenido, ni tiene por qué tener, idéntica funcionalidad sociopolítica y ética. Su censura o aprobación apriorísticas conducen únicamente a sancionar por igual todo cambio logrado por su mediación, tanto el que apuntase en una dirección liberadora como en una dirección aún más represiva y esclavizante de la persona humana.

Las revoluciones históricas habidas hasta ahora fueron movilizadas la mayoría de las veces en nombre de la libertad, o más exactamente de una mayor libertad para una mayor masa humana. Pero la libertad es un proceso socio-histórico que conlleva la alteración, e incluso la negación, de lo «establecido». La forma y el contenido de la libertad, en opinión de H. Marcuse ${ }^{6}$, van cambiando conforme al ritmo que van marcando los procesos de la historia y de las civilizaciones. Con todo, continuamente se mantiene una constante, $y$ es el hecho de vivir en un estado de relativa esclavitud en relación con las posibilidades reales de la libertad que se dan en todo momento sociohistórico. La brecha entre la posibilidad real y la actualidad, entre lo racional y lo existente nunca ha sido colmada hasta el presente. Por ello la libertad es siempre liberación, esto es, transición de un escalón dado de libertad o de nolibertad a otro que se presenta como posible en el horizonte de las coyunturas socio-históricas, quebrantando y socavando de ordinario para ello las instituciones, estructuras e intereses «establecidos». Sin embargo, puede suceder que éstos no cedan voluntariamente. De aquí que la violencia revolucionaria pueda justificarse socio-políticamente como eficaz en cuanto que puede constituir una violencia necesaria para asegurar nuevos y superiores eslabones de

6. Cfr. H. MARCUSE, o.c., pp. 147-8. 
libertad y de justicia frente a la resistencia violenta y represiva de las antiguas formas socio-políticas injustamente «establecidas».

De esta forma es como la ética de la revolución atestigua la colisión y el conflicto entre dos derechos socio-históricos: de un lado; el derecho de lo «existente y establecido»; de otro, el derecho de lo que «puede y debe ser» en cuanto que supone la disminución del dolor, de la miseria, de la injusticia y de la esclavitud, en base a unos criterios racionales e históricos para calcular las posibilidades reales del proyecto de una futura nueva sociedad.

Pero no debe olvidarse que cualquiera que sea la forma con la que se justifiquen ética y políticamente los medios violentos revolucionarios respecto a la probabilidad de arribar a una mayor libertad y justicia, y con ello, en consecuencia, a la eventualidad de violar derechos establecidos por el ordenamiento socio-político existente, incluido el mismo derecho a la vida, se dan modalidades de violencia que en ninguna hipótesis pueden resultar justificables, tales como la violencia arbitraria, la tortura, el terrorismo estricto, etc.

Pero también hay que tener presente el apunte de $\mathrm{H}$. Marcuse: en la continuidad histórica las revoluciones van estableciendo su propio código ético, constituyéndose de esta forma y en base a sí mismas en fuente de nuevas normas, de nuevos sistemas de valores. De esta forma la implantación original de determinados valores y códigos éticos y jurídicos, actualmente aprobados y aceptados de forma general, incluyó en su momento constituyente la violencia revolucionaria (cfr. los derechos surgidos a raíz de la Revolución Francesa) ${ }^{7}$.

La violencia revolucionaria no constituye en sí misma un valor. Pero la represión y subyugación que incluye pueden estar en función de unos fines que no son únicamente de índole política, sino también ética: la mayor libertad, justicia y dicha posibles en un momento y situación determinados para la mayor masa humana posible.

Toda revolución se presenta en un primer momento como «ilegítima» en cuanto que quebranta el derecho de lo «existente». Pero la escala de lo ético va constantemente transcendiendo, por su exigencia imperativa y proyectiva, lo «establecido», y ello en virtud de la continuidad y dinámica históricas en la que tal estado de cosas se originó y configuró y por lo que todo estado de cosas es alterado y anulado por otros. Es en el marco de esta dinámica sociohistórica en el que puede situarse y presentarse el proyecto revolucionario con su oferta de mayor libertad y justicia en base a unos cálculos que rebasan lo "establecido», determinando los recursos y posibilidades disponibles y los medios racionales para utilizarlos. De esta forma lo revolucionario, por su mismą función objetiva, puede ampliar el campo de la libertad y de la «humanitas», pese a los costos humanos y sociales que de ordinario supone: Aquí estriba su justificación socio-politica e histórica. Pero ésta únicamente puede verificarse post factum. Sin embargo, a pesar de que la función socio-histórica y

7. Cfr. H. Marcuse, o.c., p. 149: 
ética de una revolución no pueda determinarse con exactitud a priori, la dirección a la que apunta (progresiva o regresiva) se puede vaticinar con la seguridad de una razonable probabilidad, y esto cada vez con mayor exactitud de cálculo en base a la perfección progresiva de los cada vez más afinados medios y recursos técnicos y científicos.

Toda revolución exige costos y sacrificios socio-humanos, pero se trata del tributo que hay que pagar a la Historia, ya que ésta en sus procesos supone el sacrificio de la dicha, la libertad y la vida humanas. Se trata de la «inmoralidad» misma de la Historia, y es por esto por lo que se hace imprescindible la distinción entre sacrificios y costos legítimos e ilegítimos para que pueda hablarse éticamente de todo este asunto.

Si en este problema pudiera uno mantenerse en lo abstacto y etéreo, difícilmente podrían justificarse los sacrificios y costos subyacentes a todo empeño revolucionario. Pero desde el momento en que en el terreno concreto y real de lo socio-histórico el sacrificio y la muerte son diariamente exigidos por la misma dinámica de los procesos socio-históricos, es en base a esta «aritmética inhumana» de la Historia, tal y como la llama $\mathrm{H}$. Marcuse ${ }^{8}$, por la que pueden y deben plantearse los cálculos socio-históricos y los juicios éticos sobre la oportunidad y la posibilidad de un proyecto revolucionario, aunque implique sacrificios y costos socio-humanos.

Los recursos materiales y espirituales, las posibilidades disponibles, la medida de las necesidades vitales y no vitales satisfechas o insatisfechas constituyen el material empírico a disposición de los cálculos y análisis sociohistóricos para determinar si los recursos y capacidades disponibles en una comunidad humana están siendo utilizados de la forma más justa y racional posible. Cuando estos cálculos y análisis constatan la existencia de estructuras e intereses que están reprimiendo y bloqueando las capacidades, recursos y posibilidades de libertad y justicia a disposición de esa sociedad, entonces el derrocamiento de dichas estructuras e intereses en favor del incremento del progreso hacia la libertad y la justicia puede presentarse como sociohistóricamente justificable el movimiento socio-político que actúe en la dirección y sentido del cálculo y de los análisis. Esto tendrá que ser ratificado por el desarrollo efectivo de dicho movimiento y por la forma como conserva o rompa la relación entre los medios empleados y fines pretendidos, ya que

«...la relación entre medio y fin es el problema ético de la revolución. En cierto sentido el fin justifica los medios: cuando promueve demostrablemente el progreso humano en libertad. Este fin legítimo, el único fin legítimo, exige la creación de condiciones que faciliten y favorezcan su realización y la creación de estas condiciones puede justificar el sacrificio de víctimas como lo ha justificado a lo largo de toda la Historia. Pero esta relación entre medios y fin es

8. Cfr. H. MARCUSE, o.c., pp. 153-4. 
dialéctica. El fin para que pueda ser alcanzado, tiene que estar operante y vivo en los medios represivos. También los sacrificios implican la violencia: la sociedad sin violencia queda como posibilidad de un escalón histórico aún por lograr» ${ }^{9}$.

\section{CRITERIOS PARA ILUMINAR ÉTICAMENTE LA VIOLENCIA REVOLUCIONARIA}

El criterio decisivo es el amor como imperativo absoluto de la ética, de donde se deriva la primacía ético-revolucionaria de la no-violencia. Esto es lo que me propongo desarrollar en este punto teniendo en cuenta también las imposiciones de las situaciones concretas que pueden relativizar esta opción prioritaria por la no-violencia.

En un principio la no-violencia resulta lo más connatural con la esencia de lo revolucionario, ya que toda acción revolucionaria auténtica quiere romper el «cerco de violencia», que articula los engranajes del «sistema establecido" injusto, presentando para ello una alternativa al mismo sistema injusto y no dentro de sus coordenadas.

Los fines revolucionarios tienen que cualificar la elección de los medios. La praxis no-violenta manifiesta un respeto y una valoración de la persona humana, que deben estar en la base de toda auténtica tranformación revolucionaria radical. Esto no significa una renuncia a la eficacia, sin la que no existe ética válida en el terreno de lo socio-político, sino que supone enmarcarla en un ámbito más comprehensivo, que intenta abarcar a un tiempo las estructuras y las conciencias, de tal forma que la transformación estructural se arraigue en la estabilidad fundada en el consentimiento de las conciencias, y no en las eventualidades de la coerción. Y es que cuando la violencia alcanza su objetivo inmediato de hacer saltar las estructuras injustamente establecidas le falta aún la eficacia revolucionaria que se basa en la conversión de las conciencias.

La acción violenta se reviste de los modos que quiere combatir y se fundamenta en el principio de la victoria del más fuerte. Implica un riesgo de limitarse a invertir los papeles sin erradicar radicalmente el "estado de violencia» por lo que conlleva en sí misma componentes contrarrevolucionarios. La construcción de una sociedad plenamente nueva tiene que caracterizarse por la negación para sí misma de lo que niega para la «sociedad establecida» injusta (el reinado de la violencia) y por la afirmación para sí misma de lo que afirma para toda sociedad auténticamente humana (la implantación socio-histórica del amor y de la libertad) ${ }^{10}$.

Por otro lado, para un creyente la no-violencia encuentra unas profundas resonancias en el evangelio. Sin embargo, todo este asunto constituye un

9. Cfr. H. MARCUSE, o.c., p. 156.

10. Cfr. J. GiRARDI, Amor cristiano y lucha de clases, (Salamanca 1971), p. 67. 
problema en el que la eficacia, por una parte, y la urgencia de unas determinadas situaciones saturadas de injusticia son unos límites más allá de los cuales las técnicas no-violentas podrían en el fondo camuflar o servir de pretexto para la cobardía, el conformismo o la hipocresía ".

Quiero decir que por más que la violencia constituya una deficiencia, esto no significa ya sin más la normatividad absoluta de la no-violencia. Si la alternativa se plantease siempre entre la violencia y la no-violencia, no habría ninguna duda sobre el particular. Pero puede que no sea así como se planteen histórica y situacionalmente los problemas concretos. La opción del creyente puede plantearse entre una violencia y otra violencia, entre la violencia opresiva institucionalizada y la violencia liberadora. El problema no radica entonces en elegir entre el bien y el mal, sino en optar entre dos deficiencias éticas: o la complicidad con la violencia institucionalizada o el compromiso con una violencia liberadora.

Son los análisis de las situaciones y coyunturas concretas los que deben dictar los caminos y métodos concretos de la lucha política que el creyente debe adoptar. Es a este nivel en el que la revolución puede aparecer como la solución para una situación determinada, y la violencia como la mediación adecuada. En una situación así es cierto que la violencia revolucionaria puede constituir una deficiencia, pero sus componentes causales deben buscarse en otros factores previos, más graves por definición, y de los que la revolución intenta la liberación por medio de la violencia, cuando no son posibles ni viables otros recursos.

Renunciar a pasar por el recurso a la violencia para lograr la transformación de una situación injusta que no puede obtenerse por otros medios puede equivaler al conformismo con la injusticia más grave por definición: la «estructuralmente opresiva». Por imposición de los mismos hechos hay situaciones en que la alternativa no se plantea entre la violencia y la paz, sino entre la complicidad con el «desorden establecido» o el compromiso por la acción viable para la transformación de la situación ${ }^{12}$.

Existen situaciones que pueden imponer el recurso a la violencia revolucionaria, lo cual puede traumatizar las conciencias movidas por el amor, cuya dinámica más auténtica ha resultado en parte violada. Pero es así como funciona la historia humana, y su movimiento puede exigir la revolución para una situación determinada, y la mediación de la violencia cuando ya no existen otras soluciones. Todo esto puede parecer un «compromiso» que empaña la pureza de los ideales revolucionarios, pero hay situaciones en que las soluciones éticas «puras» no son socio-históricamente posibles, ya que se presenta

11. Cfr. M. BLAISE, Violencia liberadora y conciencia cristiana, en AA.VV.: «La violencia de los pobres», (Barcelona 1968), pp. 139-40.

12. Cfr. F. Biot. Teología de las realidades políticas». (Salamanca 1974), pp. 237-8. 
la alternativa entre una solución de «compromiso» o la renuncia a toda solución.

Por otro lado, también la no-violencia constituye una deficiencia, bien por la presión que ejerce sobre las conciencias, bien porque en ocasionies deja subsistir la «violencia establecida» que combate. En este sentido se acorta la distancia entre la violencia liberadora y la no-violencia, ya que ambas, cada una a su nivel, resultan infieles al amor que las mueve.

La no-violencia constituye una subversión de todo tipo de violencias, en la medida en que pueda moverse en unas condiciones socio-históricas en las que pueda presentarse como una alternativa tal que toda violencia, sea del tipo que sea, quede totalmente desplazada. Para ello tiene que gozar de un potencial tal que pueda alterar el equilibrio y la relación de fuerzas. Con este fin, entre otros componentes, tiene que contar con una movilización de masas dispuestas a ponerla en práctica, ya que entonces toda pretensión de violencia se perderá en una masa que le opondrá una voluntad tal, que pondrá de manifiesto su inutilidad. Pero esta movilización masiva no siempre es sociohistóricamente posible ${ }^{13}$.

La no-violencia en principio goza de toda prioridad en los planteamientos éticos y auténticamente revolucionarios. Por ello quienes deciden recurrir a la violencia revolucionaria, tienen que cargar con la prueba de la legitimación de su opción, la cual no puede presumirse, sino que tiene que fundamentarse seria y sólidamente con la presencia de una situación en la que se violan los más elementales derechos de la persona humana y con la imposibilidad e ineficacia manifiestas de otros recursos.

La originalidad de la no-violencia estriba en su repudio del recurso a la fuerza física destructiva y mortífera, incluso por las más urgentes razones de injusticia, como mediación para la solución de las situaciones injustas. Esta opción puede basarse en dos fundamentos:

a) En motivaciones ético-religiosas: para el creyente no-violento todo uso de la violencia mortífera es radicalmente incompatible con el principio evangélico del amor.

b) En motivaciones ético-políticas: el no-violento está persuadido de la ineficacia e inutilidad, a largo plazo, de los medios violentos para la resolución de las situaciones injustas. Por otro lado, los análisis de las situaciones concretas pueden ratificar científicamente, a nivel estratégico-táctico, esta convicción.

13. Cfr. B. Duclos, Los cristianos en la violencia, en AA.VV.: «La violencia de los pobres», pp. 95-127. 
4. DATOS DESDE LOS QUE SE PUEDE ILUMINAR EL PROBLEMA DE LA VIOLENCIA REVOLUCIONARIA: LA COHERENCIA CON LA TRADICIÓN

\subsection{La referencia a Jesús de Nazareth}

El dilema que se le plantea al creyente comprometido en una causa revolucionaria es el siguiente: para seguir las huellas de Jesús de Nazareth debe tener ya a priori la preferencia por la no-violencia. Pero en el caso de que las imposiciones de los cálculos coyunturales y de los análisis científicos de la situación determinen como inevitable el recurso a la violencia, so pena de renunciar a la efectividad revolucionaria dada la acorazada resistencia de los poderes injustamente establecidos, ¿tienen que ser dichas imposiciones las que decidan en su opción?, ¿o debe ser la imitación literal de la conducta personal de Jesús de Nazareth, quien rehusó siempre, a pesar de todas las imposiciones, al empleo de una violencia mortífera? ${ }^{14}$.

En cualquiera de los dos casos el creyente parece correr el riesgo de una pérdida de identidad. En el primer supuesto parece arriesgarse a quebrantar su identidad de creyente. En el segundo a erosionar su identidad de revolucionario que actualmente está relacionada con la autonomía y consistencia de las mediaciones racionales y científicas mediatizadas por los análisis coyunturales y por los cálculos técnicos de posibilidades.

La actual «teología de la revolución» intenta mostrar cómo lo revolucionario goza de un título de legitimidad en la identidad creyente. Pero la opción por ello ha de pasar por unas imposiciones, que no estuvieron necesariamente presentes en el horizonte de las decisiones de Jesús de Narareth. Estas imposiciones pueden imponer como inevitable, en determinadas circunstancias y bajo ciertas condiciones, el recurso a la violencia, si no se quiere renunciar a la eficacia revolucionaria, dadas las barreras que puede oponer al proyecto revolucionario el aparato defensivo del «sistema establecido» injusto.

14. Por lo que respecta al punto de la violencia debe tenerse por algo ya definitivamente adquirido entre los autores el hecho de la renuncia por parte de Jesús de Nazareth al empleo de la violencia mortífera. A título ilustrativo puede verse: J. COMBLIM. Teología de la revolución, (Bilbao 1973), p. 309; J. FOLLIET. Reflexiones cristianas sobre la violencia, en «Criterio», n. 1560, 1968, p. 873; O. LACOMBE. Cristianos en la violencia del mundo, en AA.VV.: "La violencia», (Bilbao 1969), pp. 263-302; A. TROCMÉ. Gesú e la rivoluzione, (Torino 1969); C. WIENER, en AA.VV.: «La violencia», (Bilbao 1969), pp. 134-5; J. e H. Goss-MAYR. Otra revolución, (Barcelona 1970), p. 19; J. J. LASERre, Matar separa de Dios, en H. e J. Goss-Mayr. o.c., pp. 29-33; F. URBina, Violencia en el mundo y en la Iglesia, (Barcelona 1970), pp. 87-8; O. CullmanN, Jesús y los revolucionarios de su tiempo, (Madrid 1971), pp. 19-24; R. CostE. Las comunidades políticas, (Barcelona 1971), p. 324; B. HÄRING, Violencia y no-violencia en el Sermón de la Montaña, en AA.VV.: «La violencia de los cristianos», (Salamanca 1971), p. 57; J. M. Diez-Alegría. Juicio cristiano de la violencia en relación con el progreso, en AA.VV.: «La Teología al encuentro del progreso", (Bilbao 1973), p. 226-36; J. W. Douglas. La cruz de la no-violencia, (Santander 1974); F. RaURel.l, Jesús y la violencia revolucionaria. Problemas de interpretación y transposición, en «Estudios Franciscanos», 75, n. 350, 1974, p. 194. 
Jesús de Nazareth se vio rodeado de unos condicionamientos determinados provenientes de la peculiaridad de su misión. En base a esta originalidad contextual Jesús rechazó todo recurso a la violencia mortífera como la actitud más coherente con el talante y los objetivos de su especial misión. Sin embargo, el contexto que rodea al creyente actual, los condicionamientos a los que se ve sometido, las imposiciones a las que debe atender, e incluso los objetivos inmediatos que persigue pueden no coincidir ni exacta ni necesariamente con los de Jesús de Nazareth. Entre estas imposiciones y condicionamientos puede figurar, en cuanto mediada por el análisis racional-político y los cálculos coyunturales sobre una situación determinada, la inevitabilidad del recurso a la violencia, si no se quiere renunciar, dada la peculiaridad de la situación, al logro de los objetivos revolucionarios que se intentan plasmar en la estructuración social concreta, y con los que el creyente intenta historificar las instancias de libertad y de justicia del mensaje de Jesús de Nazareth.

Estas reflexiones sugieren que la actitud personal de Jesús de Nazareth de «no-violencia», aunque a priori haya de adoptarse como una actitud paradigmática para el creyente, sin embargo no goza de una exclusividad tal que impida apodícticamente para todo creyente y en cualquier contexto todo recurso a la violencia revolucionaria.

Es lo que en el fondo afirma un autor de la ponderación y solera de R. Coste cuando dice:

«...concediendo una dirección dinámica a la no-violencia Cristo no ha querido prohibir a los cristianos recurrir a la legítima defensa por lo menos cuando ella parezca indispensable para proteger a los inocentes... Aquella persona que estuviese convencida en un caso determinado que el recurso a la contraviolencia era indispensable para impedir un crimen del que iba a ser víctima el prójimo, podría obrar en conciencia... ${ }^{\text {is }}$.

Jesús de Nazareth rehusó ejercer su mesianismo por vía de la coactividad política. Esto no implicó por su parte la abolición o el desprecio de lo político, sino más bien una profundización de su esencia, al despojarlo de toda mixtificación y al devolverle su verdadera autonomía, consistencia y secularidad.

Éste hecho suscita los siguientes interrogantes: ¿resulta coherente acudir primariamente a la instancia religiosa para buscar la solución a un problema, como el que aquí se analiza, que primariamente es de naturaleza sociopolítica, aunque para un creyente venga también mediado por la instancia religiosa que determina su vinculación a Jesús de Nazareth, quien, aunque adoptó una determinada postura frente a este problema, sin embargo no se lo planteó primaria y exactamente en los mismos términos políticos en que se lo formula el creyente actual?, ¿no habrá que acudir en primer lugar a la instancia socio-política, si se quiere respetar la consistencia y secularidad de lo político

- 15. R. Coste, Evangelio y política, (Madrid 1969), pp. 190-1. 
que el mismo Jesús de Nazareth quiso instaurar, para después dirigirse a la instancia religiosa y buscar en ella la mediación especial que habrá de determinar la forma específica de vivir un creyente la respuesta previa y autónomamente dictada por la instancia socio-política?

Otro problema lo constituye el hecho de que entre el dictamen de la instancia política y la mediación religiosa se diera una contradicción irreductible. En esta hipótesis el creyente perdería su identidad si secundara el dictamen de la instancia política, marginando y más aún contradiciendo las imposiciones de la mediación religiosa. Sin embargo, como se irá viendo a lo largo de este capítulo, bajo determinadas condiciones no se da esta contradicción irreductible entre un específico recurso a la violencia mortífera y el respeto de la mediación religiosa. Por lo menos esta contradición no la vio la tradicción de la moral católica en determinados casos, como ya se verá más adelante.

Jesús de Nazareth no aparece en el evangelio proponiendo una alternativa concreta a la estructuración socio-política en que vivió. Pero su preferencia por los pobres y marginados de la sociedad de su tiempo para edificar la nueva comunidad de salvación implica un fermento y exigencia de nuevas formas sociales, aunque Jesús no presentase el correspondiente programa político de tipo técnico. Por ello su actitud ante la violencia no viene determinada en primera instancia por la mediación política, sino por la religiosa. Sin embargo, el creyente actual comprometido en la transformación de la sociedad no puede prescindir de los dictámenes de la instancia política, y de aquí que su opción venga mediada por unas imposiciones con las que Jesús de Nazareth propiamente no contó. No parece, pues, que la actitud de Jesús de Nazareth pueda imponer al creyente, dado que ésto es el nivel y alcance de lo religioso, más que un estilo y unas condiciones concretas de verificar el recurso a la violencia, que previamente le haya dictado la racionalidad socio-política. No parece, pues, que la actitud personal de Jesús de «no-violencia» pueda imponer para todo creyente y en cualquier contexto la renuncia inexcusable de cualquier recurso a la violencia revolucionaria.

Seguramente si Jesús hubiera secundado el camino de los zelotes, el cristianismo no habría sobrevivido como alternativa de liberación universal y transcendente. Si Jesús no se alineó con los guerrilleros de su tiempo no fue por táctica, sino por profundos principios.

Pero el creyente de hoy no sólo se mueve en el nivel ético-religioso de los principios, sino también en el político, en el que imperan las tácticas y las estrategias. Las posibles tensiones entre los dos niveles han de resolverse viviendo y verificando las tácticas y estrategias políticas de acuerdo con las exigencias e imposiciones que dimanan de los principios ético-religiosos. Si las tácticas y estrategias políticas imponen el recurso a la violencia, habrá que hacerlo respetando los principios ético-religiosos que dimanan del paradigma que constituye para el creyente el hecho de Jesús de Nazareth, siempre que no se dé una contradicción irreductible entre ambos niveles, ya que si se diera, el creyente no podría secundar los dictámenes de la instancia política. Todo esto 
es imprescindible tenerlo en cuenta para no caer en mixtificaciones que enturbien la autonomía, consistencia y secularidad de lo político.

Jesús de Nazareth polarizó toda su ética en el amor, como el principio supremo, configurador y dinamizador de todas las opciones. Este principio del amor fue el que le impuso la repulsa de la violencia mortífera y la adopción de la no-violencia como vía de su plasmación concreta.

Sin embargo, el descubrimiento cada vez más perfecto de la densidad dialéctica del amor, la complejidad creciente de las nuevas situaciones, los horizontes cada vez más amplios de las nuevas perspectivas y la racionalidad cada vez más conseguida de lo socio-político pueden llevar a la caracterización de determinadas modalidades de la violencia, incluso mortíferas, como mediaciones de la concretización vital del principio del amor y como vías posibilitadoras de un universo de amor entre todos los hombres. Por esta perspectiva se apunta a que el creyente, en razón del mismo principio del amor que empujó a Jesús de Nazareth a rehusar la violencia, pueda recurrir, en una determinada situación y bajo determinadas condiciones, a una eventual violencia, incluso armada. Lo que no puede dejar de hacer es amar. Por ello, en la hipótesis de una opción por la violencia mortífera, tiene que mantenerse ajeno a todo "espíritu de violencia», es decir, a todo odio sistemático, a todo talante vengativo, albergando dentro de sí anhelos de paz, de reconciliación, de disposición permanente al perdón, y estando presto a romper el «círculo vicioso» de la violencia tan pronto como le sea posible.

El Evangelio no es un código de máximas éticas, sino que más bien constituye una interpelación a la integración cada vez más lograda del creyente en el ámbito de Jesús de Nazareth. La Palabra de Dios invita a la vinculación con Jesús de Nazareth, pero deja un amplio margen discrecional para que cada creyente vaya descubriendo la forma de vivir dentro de dicha relación los nuevos problemas que van surgiendo en cada situación específica. Por esta razón Pablo declaró ilegítima la violencia por razones de venganza (Rom 12,19) pero vio como bueno que el magistrado llevase la espada por razones de ejecución de la justicia (Rom 13,4).

Sin embargo, hoy y en determinadas situaciones la violencia revolucionaria puede ser percibida por el creyente como la única mediación posible para la implantación de la justicia en el orden socio-político. Esto quiere decir que tanto la violencia como la no-violencia no tienen por sí mismas el rango de principios en el Nuevo Testamento, sino de instrumentos para la verificación de los principios supremos. Fue el principio del amor quien determinó la línea no-violenta de Jesús de Nazareth y fue el principio de la justicia el que hizo a Pablo legitimar una determinada modalidad de la violencia de acuerdo con el contexto en el que se movió el Apóstol. Y siguen siendo estos mismos principios como supremos y definitivos los que pueden legitimar, de acuerdo con el nuevo contexto en que se mueve el creyente actual, el recurso a la violencia revolucionaria como instrumento de su verificación e implantación en una determinada situación. 
Considero que el problema de la violencia en su vertiente socio-política no tiene en el Evangelio una respuesta literal directa e inmediata. Es cierto que éste ofrece una línea concreta respecto al problema de la violencia, pero no directamente a un nivel propiamente político, ya que la opción de Jesús de Nazareth tiene una ligazón inmediata con su misión mesiánica. Por ello opino que no es legítimo exigir al Evangelio la presunción, de una vez por todas, de la determinación apodíctica del comportamiento de todo creyente para cualquier momento y situación, sobre todo en el problema que aquí se analiza en el que actualmente se encuentra condicionado por instancias que no estuvieron directamente presentes en el horizonte de las decisiones de Jesús de $\mathrm{Na}$ zareth, si bien la conducta de éste ofrece una línea, un estilo y un talante de comportamiento, cuyas imposiciones también tienen que mediar en la opción del creyente y en su verificación.

La liberación de toda forma de violencia pertenece a la esencia del hombre, pero ésta no informa por completo aún su existencia, y ésta última a su vez se encuentra a merced de las contradicciones y posibilidades de cada momento socio-histórico. La esencia habita en el futuro, y éste por ahora únicamente puede ser apropiado por vía utópica. Los análisis racionales y los cálculos científicos de las condiciones y posibilidades de cada momento y situación permiten fraguar los proyectos concretos, pero sin agotar el horizonte utópico. Ésta es la razón por la que ninguna revolución puede reivindicar la realización de la totalidad de lo posible.

Jesús de Nazareth desenmascaró la trama de violencia que empaña la existencia humana, y proclamó con su conducta la liberación de toda violencia como auténtica esencia de la condición humana. Los contenidos sociohistóricos de la violencia que Jesús de Nazareth impugnó y sufrió no son idénticos a los que afligen al hombre actual, pero el Evangelio no se propone dar la formulación concreta de la violencia, sino su razón de fondo, del mismo modo que tampoco se propone programar la alternativa revolucionaria concreta que tiene que engendrar la nueva sociedad inmune a todo virus violento. Por ello constituye un error querer hacer desempeñar al Evangelio el papel de los análisis científicos por los que el hombre aprehende las causas de sus esclavitudes socio-históricas y proyecta las mediaciones de su eliminación. Pero también es un error la marginación de las instancias evangélicas a la pura interioridad del creyente.

Jesús de Nazareth no impugnó la violencia desde dentro de los engranajes políticos, sino que salió a su encuentro desde la instancia profética. No fue un artesano de la política, sino que se movió en el terreno que constituye el subsuelo y substrato de las coyunturas socio-históricas. Por ello exigir al Evangelio la competencia y responsabilidad de decidir por sí sólo y de forma técnica si una revolución concreta y en una determinada situación debe ser o no políticamente violenta, supondría actualmente, en el nivel alcanzado por la secularidad de lo político, utilizarlo para funciones que no son propiamente las suyas. Con todo, el Evangelio debe atravesar de alguna forma la articulación 
de todo proyecto que hace el creyente, también el referente a la programación violenta o no de una revolución.

La seriedad de su Encarnación puso a Jesús de Nazareth, como a cualquier hombre, a merced de la violencia, haciendo particularmente de su muerte en cruz una requisitoria de las coordenadas violentas de este mundo.

Las bienaventuranzas evangélicas constituyen la revelación de la universidad y posibilidad de la condición humana en cuanto situada más allá de sus condiciones socio-históricas de violencia. De aquí la constante situación de "suspensión» en que se encuentra el creyente de cara a todo programa político de liberación, ya que, a pesar del fervor con que se adhiere a él, nunca agotará la totalidad de las bienaventuranzas evangélicas.

Como el esfuerzo del creyente tiene que dirigirse a la construcción de un mundo distinto a éste, tan preñado de violencia, resulta acuciante para él la cuestión de la mediación por la que dicha construcción debe pasar. En este sentido la no-violencia es la mejor forma de acercar lo más posible al presente el futuro buscado. Pero no está exenta de riesgos. Uno de ellos es el de poder dejar libre el campo para el despliegue de la violencia opresora, que, quizá más que ninguna otra, es la que bloquea el avance hacia ese futuro. Para ello la no-violencia al menos tienen que sentirse solidaria con aquellos que, en su lucha contra la más flagrante de las violencias, la violencia opresora institucionalizada, no pueden renunciar a las imposiciones de lo político en una situación concreta, y se ven precisados a recurrir a la violencia revolucionaria para extirpar aquella otra violencia.

Las opciones políticas tienen como algo irrenunciable la eficacia sociohistórica y la referencia a las coyunturas concretas, con todas sus limitaciones e imposiciones, y por ello, sólo pueden remitirse a las bienaventuranzas evangélicas como al término profético último de una liberación humana que en primera instancia se ve precisada a adoptar las mediaciones que le impone la propia consistencia y autonomía de lo político. De esta forma es como la violencia revolucionaria es también para el creyente, antes que nada, un asunto socio-político, pero con una referencia también a lo profético y a lo evangélico, que tienen que mediar en las determinaciones de su verificación concreta y tienen que constituirse en fermento activo de su proceso de verificación.

La vía política de erradicación de la violencia tiene que ser la que se muestre más eficaz para este fin, y por ello la posibilidad de que pueda constituirla el mismo recurso eventual a una determinada modalidad de la violencia, para remover las condiciones estructurales y coyunturales que engendran, transmiten y propagan el imperio de la violencia. Esta vía se funda inmediatamente en las prospecciones que la razón humana efectúa sobre una determinada situación política. En esta primera instancia analítica lo político es autónomo de cara a las imposiciones de la fe. Pero la conciencia programática del creyente no se agota en los límites estrictos de la acción política, sino que superándolos, tiene que encaminarse hacia los horizontes últimos, que dotan de consistencia radical a toda transformación revolucionaria. Ésta es la razón de 
que lo político para un creyente no pueda desentenderse por completo de la creencia. Es también la razón de que una actitud como la de la no-violencia, que es primordialmente de índole profético, tenga su carta de ciudadanía en lo político, pero sin poder forzar su consistencia y autonomía, sobre todo cuando las imposiciones de una situación determinada pueden exigir al creyente un aplazamiento de esa anticipación del futuro libre de toda violencia, que lleva en su seno la actitud de la no-violencia.

\subsection{La tradición teológica}

La moral tradiccional católica no ignoró el problema de la violencia. Lo abordó a propósito de ciertas cuestiones típicas, particularmente la de la guerra justa (violencia bélica), la de la legítima defensa frente a un agresor injusto (violencia interindividual), la de la pena de muerte (violencia jurídicopenal), la del tiranicidio. Sobre todos estos temas se fue elaborando no sólo un catálogo de principios básicos, sino también una detallada casuística, que determinaba al pormenor las directrices de actuación en cada circunstancia concreta. Para la moral tradicional hubiera resultado un despropósito la condenación y proscripción indiscriminada de toda forma de violencia. Disconforme en un principio con la eventualidad de la violencia, no tuvo más remedio que reconocer su licitud para determinadas situaciones y bajo concretas condiciones, cuando suponía la única forma posible de defenderse y de defender al prójino frente a un previo ataque violento injustificado ${ }^{16}$.

La legitimidad que subyace a la violencia defensiva personal ante el injusto agresor ha sido la que fue suministrando el esquema normativo a las demás formas de violencia reconocidas como lícitas: la guerra defensiva o de resistencia frente al enemigo invasor, la insurrección frente al tirano, y la pena de muerte con las restantes medidas penales con las que la sociedad pretende disponer para defenderse de sus miembros considerados peligrosos. Todo este cuadro fue recibiendo en la vida socio-histórica de la Iglesia una hermenéutica y una praxis bastante holgadas, y así este esquema también funcionó para justificar las guerras de cruzadas y las campañas contra los herejes, en cuanto que se trataban de una violencia física para defenderse de unas previas «agresiones» de índole espiritual.

Actualmente el ilimitado potencial destructivo de las sofisticadas armas nucleares ha sometido a revisión, cuando no a contestación, la hasta ahora pretendida licitud de la guerra entre las naciones, de igual forma a que la acumulación en manos de los poderes públicos de eficaces medios de control ha hecho otro tanto con la de la pena de muerte. Cada vez es más patente que la

16. R. HeCKel, El cristiano y el poder, (Barcelona 1963), pp. 148-51 y G. HigueRA, ¿Evolución o revolución?, en «Sal Terrae», 56, n. 6, 1968, pp. 415-6, sintetizan muy bien los principios fundamentales, fijados por la moral clásica, que dicen relación al problema que se analiza aquí. 
guerra, lejos de solucionar los conflictos, los agudiza hasta amenazar con destruirlo todo. Por otro lado, la autoridad, para mantener los niveles más elementales de convivencia, dispone de recursos más eficaces y menos atroces que la ejecución de los delincuentes. Por todo ello la ética actual cada vez parece más decidida a descartar ambos tipos de violencia de sus cuadros de licitud.

Con todo, respecto a la guerra justa, algunos como R. Coste ${ }^{17}$ opinan que sus principios tradicionales pueden estirarse para encontrar aplicación y vigencia aún en las coyunturas actuales. $R$. Coste señala concretamente la eventualidad de la guerra civil revolucionaria en defensa de los derechos fundamentales de una población ante la violencia opresora de las esferas gubernamentales, dada la convencionalidad del instrumental bélico que de ordinario todavía se emplea en estos casos.

Es en la hipótesis de la guerra internacional donde el principio de la proporcionalidad plantea los mayores problemas, dada la calidad destructiva de los modernos arsenales nucleares, hasta el punto de que la mayoría ha relegado a los archivos la teoría de la "guerra justa».

Es cierto que en una especulación puramente teórica se puede concebir la hipótesis en la que el empleo de los modernos armamentos pudiera llevarse a cabo respetando los principios de la violencia bélica justa. Pero la posibilidad de una guerra atómica limitada entre naciones que disponen de armas nucleares es una peligrosa ilusión. Por ello la Gaudium et Spes no se limitó a exigir la atenuación de las crueldades de la guerra (n. 79), la condenación de la guerra total (n. 80) y de la carrera de armamentos (n. 81), sino que también proscribió la guerra como mediadora de los conflictos, urgiendo la acción a escala mundial para erradicarla por completo.

Santo Tomás consideró la posibilidad de una guerra entre Estados, pero no la de una guerra civil. Sus argumentos descansaban en una peculiar teoría filosófica sobre el Estado. Para la mentalidad de su tiempo únicamente cada Estado constituía la sociedad perfecta y completa. La guerra exterior entre dos sociedades perfectas no amenazaba de por sí a la unidad de la comunidad política del Estado, sino que más bien la robustecía. La guerra civil era la que escindía el armazón de la sociedad y la desintegraba. Por ello su ilicitud.

Para la conciencia del hombre contemporáneo la sociedad completa la constituye el universo habitado por el hombre. La guerra internacional se reviste en este esquema de las notas que la teoría tradicional atribuía a la sedición, en cuanto amenaza del equilibrio unificador de la sociedad internacional. Por ello, a partir de Pío XII, la Iglesia en su catequesis oficial ha encontrado cada vez más reparos para justificar cualquier tipo de guerra exterior entre los pueblos.

17. Cfr. R. Coste, El problema de la guerra justa, en «Sacramentum mundi», (Barcelona 1973), pp. $346-8$. 
Sin embargo, el fondo de la teoría se está reintroduciendo, bajo nueva versión, por el camino de la guerrilla y de la guerra civil revolucionaria en las que pretenden encontrarse actualmente las instancias éticas que justificaban la violencia bélica para santo Tomás y la tradicción moral ${ }^{18}$.

Pero hay que tener presente la advertencia que sobre este asunto formulan algunos: para ellos ni siquiera en la época de las armas convencionales resultó viable el discernimiento entre bellum iustum e iniustum a base de los principios fijados por la teoría sobre la «guerra justa». Y así para J. P. Riga ${ }^{19}$ no existe evidencia concluyente de que la doctrina de la guerra justa haya tenido oportunidad de aplicación como instrumento éticamente iluminador de las decisiones políticas referentes a la guerra.

Por lo que respecta al principio en torno al derecho de insurrección enuncia las condiciones de su licitud en términos tan universalizantes, que en la práctica resulta muy difícil conjugar cuáles son las posibilidades concretas de su aplicación.

En el fondo su utilidad parece reducirse a la justificción de insurrecciones ya triunfantes y cuando ya se puede analizar su proceso «a posteriori». Pero esta doctrina no parece estar dotada de la capacidad suficiente para movilizar y legitimar una iniciativa propiamente revolucionaria, entre otras razones porque lo insurreccional no cuadra exactamente con lo revolucionario.

La problemática planteada por la insurrección y el tiranicidio encaja más bien en el contexto de la cultura y política grecorromanas y sus derivaciones. En dicho contexto se conciben como definitivas las estructuras socio-políticas. Lo que más se puede pretender modificar son las personas responsables del gobierno de un pueblo o, cuando mucho, las formas jurídicas de gobierno. Pero su fondo estructural resulta intocable. Por ello la sedición y el tiranicidio, para la doctrina tradiccional, sólo pueden referirse a las personas que ocupan el poder o a la manera concreta de gobernar, pero no pueden afectar propiamente a un cambio estructural total, que es precisamente en lo que consiste la esencia de lo revolucionario.

Con todo, la doctrina tradicional sobre este punto es en sí misma coherente y, cuando menos, muestra cómo ya para la moral clásica una determinada violencia, incluso mortífera como el tiranicidio, podría ser legitimada en razón de las finalidades socio-políticas y éticas para las que se empleaba.

En la actualidad las tipificaciones de la violencia que se han ido agudizando y que con más seriedad y urgencia preocupan a nuestra época son las de la violencia represiva para mantener la violencia opresiva de los «sistemas establecidos» injustamente y la violencia revolucionaria empeñada en desmontar estos sistemas así articulados. Prácticamente puede afirmarse que el fenó-

18. Cfr. R. Bosc, La violencia y la no-violencia en el pensamiento de la Iglesia, en S. GALILEA, M. Osea, A. GaETo, La vertiente política de la pastoral, (Quito 1970), pp. 47-8.

19. Cfr. J. P. RigA, Iglesia y Revolución, (Santander 1968), pp. 60-3. 
meno de la violencia se encuentra de ordinario hoy polarizado en torno a la represión y a la revolución, y que es en este espacio en el que con mayor preferencia continúa abierto el debate ético sobre la violencia, sin que con ello quiera decirse que no se siguen dando episodios de delincuencia vulgar y de conflictos bélicos de corte más clásico.

La moral tradicional estaba montada sobre la tipología de dos modalidades de violencia, cualitativamente distintas: la violencia del que agrede (condenada) y la del que se defiende (permitida, si bien no siempre prescrita, en cuanto única forma de repeler el ataque y de preservar la propia integridad). Este esquema aún guarda aplicación para la actual polarización de la violencia en la tipología represiva-revolucionaria, y de hecho la mayoría de los autores continúa acudiendo a él cuando se trata de justificar el recurso a la violencia ${ }^{20}$. Yo por mi parte sí que tendré en cuenta este clásico principio de la «legítima defensa».

Al recordar los principios más clásicos de la tradición moral, no debe olvidarse que la ética no puede hacer abstracción de una objetividad en la que frecuentemente, y a pesar del propio sujeto, hay que optar por un valor ético en detrimento de otro, o hay que elegir el «mal menor» posible, o hay que renunciar a la pureza total de las acciones. A veces la bondad ética, dentro de una dinámica de la mayor autenticidad posible, tiene que conformarse con la provisionalidad, la limitación y la deficiencia. La Historia está jalonada de situaciones en las que los «conflictos de valores» van marcando el ritmo de perfeccionamiento de la praxis ética, hasta que llegue el momento de la consumación escatológica en la que desaparecerán los conflictos y deficiencias que constituyen la carga de nuestra actual condición humana. Pero toda ética que quiera anticiparse al final de los tiempos ha de resultar forzosamente inútil, por ahistórica.

La ética no debe hacer la más mínima concesión a la «violencia por la violencia» pero debe tratar de responder a la cuestión que plantea «la violencia por la justicia», porque en realidad la verdadera alternativa que se le plantea al creyente comprometido en una revolución auténtica no es en pro o en contra de la violencia, sino en pro o en contra de la justicia. Pero una vez que se ha optado por la justicia con toda radicalidad y seriedad, es cuando puede presentarse, en virtud de las imposiciones de la situación concreta, la opción por la violencia revolucionaria en cuanto posible mediación de la justicia, y,

20. Un ejemplo lo constituye el informe que se preparó para la Conferencia Episcopal Latinoamericana reunida en Medellín (Cfr. H. FEsqueT, Una Iglesia en trágica situación, (Bilbao 1970), pp. 67-9).

También pueden verse: J. M. GonZÁlEZ-Ruiz, El cristianismo y la revolución, en «Surge», 25, 1967, pp. 486-7; G. VACCARI, Teologia della rivoluzione, (Milano 1969), p. 244; H. GollwIT. ZER, Die reichen christen und der arme Lazarus, (Munich 1969), pp. 75-80; H. CHAIGNE, Bogotá y la revolución necesaria, en AA.VV.: «La fe, fuerza histórica», (Barcelona 1971), p. 186; E. Chiavacci, Teología y revolución, en AA.VV.: «Revolución», (Pamplona 1972), p. 190. 
como tal, en cuanto instrumento relativizado. Y es entonces cuando para la clarificación ética de esta eventualidad se puede acudir a los principios de la tradición moral que resulten pertinentes.

\section{VALORACIÓN ÉTICA DE LA VIOLENCIA REVOLUCIONARIA}

F. D'hoogh ${ }^{21}$ ha calificado de abstraccionista la doctrina tradicional que hablaba de la bondad o maldad intrínseca de determinados actos. Según los manuales estos actos venían determinados en sí mismos moralmente por su finis operis. Las circunstancias, las finalidades y las intencionalidades a lo más sólo podían aumentar o disminuir la previa cualificación ética que en sí mismo ya guardaba el acto. El principio fundamental en que se apoyaban estos razonamientos era: «bonum ex integra causa, malum es quocumque defectu». F. D'hoogh se pregunta si todo este montaje resulta viable en la práctica, ya que ante este mundo de disquisiciones no se puede evitar la impresión de encontrarse frente a una especie de alquimia moral.

En realidad lo que resulta intrínsecamente bueno, al margen de toda circunstancia, es el amor. En consecuencia, lo que es intrínsecamente malo es el desamor, el no-amor o el odio. Por ello no se puede pretender fijar la ética cristiana en un código de actos con una cualificación ética ya previamente determinada a priori por razón de sí mismos, con una pretendida objetividad que estuviera al margen de su vinculación o desvinculación con el amor. La ética cristiana debe consistir en la articulación del amor con un universo de relatividades por medio de una casuística que sólo tiene sentido en referencia a dicho amor. La reflexión moral ha de desarrollar esta estrategia del amor y la casuística debe trazar sus tácticas concretas.

Según el esquema tradicional de los manuales de moral el «no matarás» constituye un veto absoluto frente al que nadie puede arrogarse el derecho a decidir sobre la vida humana. Sin embargo, se permite «matar para defenderse». Con esta forma de razonar se está sugiriendo que existe algo que no encaja en todo este cuadro argumental, y que lo está poniendo en cuestionamiento y revisión ${ }^{22}$.

La definición de mal intrínseco, para que pueda darse, precisa del concurso de unos determinados componentes. Toda definición, si quiere ser rigurosa, tiene que estar acotada por unos límites estrechos, determinada por unas finalidades y esclarecida por unas distinciones.

El hecho de matar a una persona no constituye sin más un mal intrínseco,

21. Cfr. F. D'ноОGн, Los actos morales particulares, en AA.VV.: «El dinamismo de la moral cristiana», (Salamanca 1971), p. 234.

22. Cfr. F. D'нооян, Los actos morales particulares, en AA.VV.: «El dinamismo de la moral cristiana», (Salamanca 1971), pp. 234-5. 
pero una determinada modalidad (el homicidio o asesinato) sí que es un mal intrínseco. Para que el matar sea un homicidio tiene que estar enmarcado en unas circunstancias concretas y motivado por unas intenciones determinadas. Si no se dan éstas, o existen otras muy distintas, el hecho de matar a una persona humana, puede no constituir un mal intrínseco, ya que se dan circunstancias (la legítima defensa) en las que se puede tener derecho a matar. El homicidio, en cuanto mal intrínseco, incluye una circunstancia y una finalidad, faltando las cuales, aún tratándose del mismo acto material de matar, este acto puede recibir otra cualificación ética muy distinta.

La bondad o maldad éticas de los actos humanos vienen mediatizadas (no digo determinadas) por el contexto y la intencionalidad en que se enmarcan ${ }^{23}$. El «finis operis», o lo que es lo mismo, la objetividad del acto, no puede ser pura y simplemente elaborado o deducido de la mera «fisis» del acto. Si se dice que el matar es en sí mismo, objetivamente, un mal intrínseco, no debe olvidarse que esta objetividad tiene que contar para ello con el concurso de un contexto, una finalidad y una intencionalidad, sin las cuales no puede ser cualificado de homicidio como tal, sino que tal vez de legítima defensa, y de esta forma poder ser juzgado desde claves éticas completamente distintas. Por ello una de las fuentes de la posible justificación de la violencia revolucionaria estriba en el peculiar contexto situacional en que se mueve y en sus finalidades y motivaciones concretas, aunque algunos de sus actos puedan ser exactamente los mismos, desde la perspectiva material, que los del homicidio, es decir, el hecho de dar muerte a una persona humana.

$P$. Knauer formula la siguiente tesis:

«El mal moral se realiza sólo en la causación o permisión de un mal físico no justificado por un 'motivo proporcionado'» ${ }^{24}$.

En el fondo se está queriendo decir lo mismo que santo Tomás cuando, a propósito del principio del doble efecto, afirmaba que nada impide que un solo acto tenga dos efectos, de los cuales uno solo es el pretendido y el otro resulta «per accidens» 0 "praeter intentionem» ${ }^{25}$.

En la actualidad este viejo principio tiende a ser formulado por algunos autores de la forma siguiente: el efecto malo de una acción personal puede permitirse, si no es querido en sí mismo, sino indirectamente y queda contrapensado por un «motivo proporcionado» ${ }^{26}$.

Esta formulación difiere de la de santo Tomás en más de un aspecto, si bien más desde un punto de vista formal que por lo que respecta a los conteni-

23. Cfr. F. D'нооGн, o.c., pp. 237-8.

24. P. KNAUER, El principio del «doble efecto» como norma universal de la moral, en "Selecciones de Teologian, 7, n. 27, 1968, p. 266.

25. Cfr. Summa Theologica, II-II, q.64, a.7 in corpore.

26. Cfr. P. Knauer, o.c., p. 268. 
dos. Santo Tomás exigía que el acto fuese proporcionado a su fin, en tanto que en la actual formulación la exigencia fundamental se ha desplazado hacia la cuestión del «motivo proporcionado». Sin embargo, en el fondo, se trata de idéntica exigencia en la práctica, si ambas formulaciones se comprenden rectamente.

Dado que hoy todo el peso de la argumentación ética gira en torno a la cuestión del «motivo proporcionado», el problema decisivo radica en la determinación de la proporcionalidad del motivo para que el efecto de la acción, cuando se trata del efecto malo, no sea querido «directamente» tal y como exige el principio del doble efecto. Es un problema en el que se juega la objetividad de la ética de la violencia revolucionaria, ya que si el hecho de matar, que de ordinario conlleva la violencia revolucionaria, no tiene que ser algo querido ni buscado en sí mismo, sino en función de los fines marcados por el proyecto revolucionario, el problema central radica en determinar si dichas finalidades resultan ser en la situación concreta un «motivo proporcionado» para que los efectos de la violencia revolucionaria, entre los que puede encontrarse el hecho de matar, efectivamente no puedan ni deben ser considerados como «directamente» buscados y queridos desde la perspectiva ética.

En otras palabras: la cuestión central estriba en si los bienes de justicia y libertad que tiene que acarrear una revolución, cuando es auténtica, pueden justificar o no la permisión o causación de la violencia revolucionaria, entre cuyos componentes puede encontrarse el hecho de matar a la persona humana.

Tradicionalmente se ha catalogado a unos comportamientos de «intrínsecamente» malos. Otros estarían únicamente dotados de una malicia «extrínseca», y su permisión ética estaría en función de que se diera un «motivo proporcionado» para ponerlos en práctica. Sin éste resultarían igual y absolutamente prohibidos, y por tanto en el fondo vendrían a convertirse en «intrínsecamente» malos. El nudo de la cuestión radica, pues, en si se da o no un motivo proporcionado para la permisión o causación del mal «extrínseco».

Es decir, mientras únicamente se considere una acción en el marco de su fenomenología «externa», al margen de toda conformación socio-humana, resulta imposible determinar su eticidad. Sólo cuando consta si su motivo, intencionalidad o finalidad resultan proporcionados o no se puede llegar a una valoración ética. En concreto, el homicidio o asesinato es un mal «intrínseco», porque por definición constituye el acto de quitar la vida a otra persona sin que se dé un «motivo proporcionado». Si éste existe, aun tratándose de la misma acción fenomenológica, la valoración ética puede variar, y de esta forma la legítima defensa, aunque pueda implicar el hecho de matar, no constituye un mal ético, y también no puede constituirlo por extensión el hecho de la violencia revolucionaria, cuando sus motivaciones y finalidades resultan proporcionadas, ya que puede constituir una aplicación de la legítima defensa a nivel colectivo. El hecho de matar, pues, no es sin más un mal intrínseco. Es la existencia o no de un «motivo proporcionado» lo que lo 
cualifica éticamente, y de esta forma es como la violencia revolucionaria, aunque implique el hecho de matar, si está arropada por un «motivo proporcionado», puede resultar éticamente justificable.

Son bien conocidas las argumentaciones morales tradicionales acerca de que las leyes naturales negativas obligan «semper et pro semper» (por ejemplo: «no matarás) en tanto que las afirmativas obligan «semper sed non pro semper» (por ejemplo: respetar la vida). Es decir, que en el caso de las leyes afirmativas un «motivo proporcionado» puede eximir de su obligatoriedad. $\mathrm{Si}$ éste no se da, ya que no es posible tal exención, la ley afirmativa funcionará como si en realidad fuera negativa. Pero esto quiere decir también que la ley negativa resulta contenida en la afirmativa, y que, por tanto, su aplicación está en función de la cuestión acerca del «motivo proporcionado».

Por otro lado siempre existe la obligación de que el mal permitido o causado en virtud del «motivo proporcionado» sea el menor posible, tal y como exige otro viejo principio moral. Es más, la obligación positiva es en toda hipótesis una llamada a la búsqueda continua de la solución mejor para cada situación concreta.

Así pues, la obligatoriedad que subyace a las leyes negativas, como la del «no matarás» que es la que aquí interesa, es la de una absoluta prohibición de permitir o causar el mal moral (la muerte) «directamente», es decir, sin que se dé una motivación proporcionada. El no cumplimiento justificado de una ley positiva como la de «respetar la vida» consiste en la permisión o causación de la muerte de forma «indirecta», en cuanto que se dio un "motivo proporcionado» para no respetar la vida humana ${ }^{27}$.

Pero en todo momento queda pendiente un interrogante: ¿cuándo el motivo de una acción, en este caso la de matar a una persona humana en la revolución, resulta «proporcionado»? Es decir, supuesto que la violencia revolucionaria brota de un motivo (los fines de la revolución, que por hipótesis tienen que constituir un bien, dada la situación en que se mueve la revolución, para que dicha violencia pueda verse legitimada), su motivación debe resultar «proporcionada». ¿Qué supone todo esto en concreto?

$P$. Knauer responde de la siguiente forma:

«...los bienes pretendidos deben ser proporcionados a los males que llevan consigo y predominar sobre ellos. Pero, ¿en qué sentido debemos establecer la comparación si se trata de bienes no cuantitiva, sino cualitativamente distintos, de valores entre sí inconmensurables, sin medida común?».

Esta comparación es sólo posible si primeramente constatamos cuál es la función que un valor desempeña respecto del otro valor. En el fondo lo que se ha de lograr es que la acción sea de tal modo «proporcionada» al valor pretendido, que éste pueda ser obtenido en la mayor medida posible, tenida en cuenta la totalidad del contexto real...» ${ }^{28}$.

27. Cfr. P. Knauer, o.c., p. 269.

28. Ibidem, p. 270. 
En toda revolución se da una estructura de pérdida y otra de ganancia desde la perspectiva ética. En este contexto, las acciones que conllevan deficiencias o males éticos pueden resultar legitimadas moralmente si guardan una razonable proporción entre los mínimos males posibles y los mayores bienes o provechos posibles. Para ello es decisivo que las consideraciones y los cálculos se enmarquen dentro del contexto total y en la forma más objetiva posible. La legitimidad ética estriba en este sentido en la mejor realización posible de los valores pretendidos dentro de la totalidad de la situación. Estas consideraciones se apartan en cierto sentido del estrecho rigorismo moral del principio que exige la búsqueda del mayor bien posible, y se acerca más a aquel principio que se conforma con que se permita el menor mal posible, todo ello dada la precariedad ética de la mayoría de las situaciones humanas que se plantean a las conciencias, sobre todo en un contexto tan conflictivo como el revolucionario.

En consecuencia,

«...tiene que haber una razón proporcionada que, teniendo en cuenta la existencia humana total, hace aceptable el acontecimiento del mal físico... En otras palabras, la moralidad del acto exige que éste sea proporcionado al valor que se pretende conseguir. Dentro de esta proproción los pasos intermedios participan de esta moralidad» ${ }^{29}$.

Es decir, que un acto con la misma fenomenología material puede recibir configuraciones ético-humanas distintas en función de las circunstancias, de la situación, de las finalidades, de la intencionalidad, en una palabra, del contexto total en el que se sitúa. De esta forma el mismo acto fenomenológico de martar a una persona humana puede recibir valoración ético-humana distinta según se trate de un homicidio, de un acto de justicia o de una legítima defensa (estas dos últimas posibilidades son las que pueden contemplar el hecho de matar que de ordinario implica la violencia revolucionaria). Así es como el mismo acto material puede constituir un acto éticamente distinto secundum speciem moralitatis en cada una de las hipótesis ${ }^{30}$.

Con todo lo dicho no se pretende afirmar que el fin justifique cualquier tipo de medios, pero sí que el fin «determina» el sentido ético y socio-humano de los medios. Si el fin puede ser la justicia, la libertad o la legítima defensa, como por hipótesis ha de acaecer en una auténtica revolución, el hecho de matar a una persona humana que puede implicar el medio de la violencia revolucionaria «participa» del sentido ético y socio-humano que tienen los fines, y de esta forma es como puede darse el «motivo proporcionado» que permita la puesta en marcha de una acción de este tipo. Por otro lado, tanto los medios

29. C. J. van Der Pol, El principio del doble efecto, en Ch. E. Curran: «¿Principios absolutos en Teología Moral?», (Santander 1970), p. 199.

30. Cfr. Summa Theologica, I-II, q.1, art. 3, a.3. 
como los fines hay que encuadrarlos en todo su contexto socio-humano para poder determinar su eticidad. Los medios (y no hay que olvidar que la violencia revolucionaria tiene éticamente una estricta razón de mediación), como estadio intermedio del resultado final que se persigue, así como también los posibles "efectos indirectos» que puedan estar más o menos ligados a dicho resultado, adquieren su sentido propio y su valoración ética de toda la estructura global de la situación total, en la que también están implicados los fines.

Lo decisivo, pues, para determinar la eticidad radica en la totalidad de las interrelaciones socio-humanas. De esta forma es como tiene que abordarse un problema socio-político como el de la violencia revolucionaria ${ }^{31}$. El principio de que «el fin no justifica los medios» es una de las más fuertes objeciones que pueden presentarse al recurso a la violencia revolucionaria. Pero en el problema que aquí se analiza lo que en el fondo quiere significar es que el fin no puede justificar un mal intrínseco, ya que si el fin no pudiera justificar los medios, ¿qué otra cosa los podría justificar? Ya se ha hablado antes de cómo debe entenderse en todo este asunto la cuestión del «mal intrínseco». El hecho de matar a la persona humana no constituye sin más un mal intrínseco, ya que de lo contrario jamás la ética hubiera podido permitirlo en ninguna hipótesis, y no podría existir el capítulo moral de la legítima defensa. Se puede, pues, afirmar que el «fin justifica los medios» siempre que éstos no sean en sí mismos y por definición intrínsecamente inmorales. Dado que éste no es el caso de la violencia revolucionaria, ésta puede quedar justificada éticamente por los fines de la revolución, es decir, cuando exista un «motivo proporcionado» para emprenderla.

Uno de los problemas centrales es en todo momento el de la adecuada formulación de lo que constituye un «mal intrínseco». El homicidio lo es por su propia naturaleza, pero en la legítima dłfensa el mismo acto material de matar a la persona humana ya no hay que considerarlo como homicida, $y$, por extensión, otro tanto puede suceder en la violencia revolucionaria, ya que ésta puede ser una aplicación a nivel colectivo de la legítima defensa. De aquí que en la determinación de si el acto de matar a la persona humana resulta ser homicida, y como tal injustificable en cualquier hipótesis, además de la intencionalidad del agente tiene que intervenir también el contexto global de la situación. De esta forma un mismo acto material (el de matar a la persona humana) que en una situación y de acuerdo con una determinada finalidad e intencionalidad resulta ser homicida, y por tanto inmoral, en otro contexto (el revolucionario) y en virtud de otras intenciones y finalidades (las revolucionarias) puede resultar éticamente legitimado.

La clarificación de la cuestión acerca del mal intrínseco ha seguido un ritmo socio-histórico y sigue estando sometida a una determinación y concreción progresivas. En cierto modo va reflejando el grado de sensibilidad ética de ca-

31. Cfr. C.J. van DER POL, o.c., pp. 206-7. 
da momento cultural de la humanidad. Las perspectivas sobre el contenido de una noción se van enriqueciendo a partir de una inacabada reflexión sobre las nuevas situaciones existenciales y sobre los contextos concretos. Es por esto por lo que una adecuada formulación del «mal intrínseco» no puede prescindir de un cierto «situacionismo». De esta forma se hace posible mantener la vigencia de las normas universales (como la del «no matarás»), pero a un tiempo se va tomando en serio la dinámica de la historia y la inexorable relativización que ella va imponiendo a las normas. El homicidio será inmoral, pero no todo acto de matar constituye sin más un homicidio, y por tanto no todo acto de matar es ya a priori éticamente injustificable ${ }^{32}$.

De esta forma en los ámbitos revolucionarios se ha ido llegando, a partir de las perspectivas éticas contempladas por la legítima defensa, a la justificación, en virtud de las finalidades revolucionarias, de las privaciones de vidas humanas, calificadas de inmorales por bloquear el impostergable cambio socio-político hacia la libertad y la justicia en una situación de injusticia y opresión insostenibles. El hecho de matar debe ser juzgado aquí en el marco de unas determinadas finalidades de libertad y de justicia pretendidas, y dentro del contexto de una serie de imposiciones estratégicas, de condiciones y de circunstancias.

Por otro lado, el fin es lo único que puede justificar los medios, siempre que éstos no sean un mal intrínseco, y el matar no lo es en sí mismo, a no ser que el contexto concreto lo configure como un homicidio. Son, pues, los fines de la revolución los que pueden justificar éticamente la mediación de la violencia revolucionaria. La justicia y la libertad pueden tornar en lícito lo que en otro contexto y bajo otras finalidades resultaría ilegítimo. La bondad o malicia de una acción no radica tanto en sí misma cuanto en la concurrencia de la totalidad de los factores que la integran, tales como los medios, las motivaciones, las finalidades, las intencionalidades y las consecuencias previsibles.

Un medio es ilícito cuando no se da un «motivo proporcionado» que justifique su puesta en marcha. Mientras se pretendan unos fines de una forma auténticamente proporcionada a dichos fines, los medios por los que pasa su verificación quedan «determinados» por dichos fines, a no ser que estos medios estén ya previamente determinados por sí mismos, por tratarse de «males intrínsecos». Por ello cuando se trata de «medios proporcionados» a los fines y que no sean en sí mismos «males intrínsecos», los males eventuales que de ellos puedan derivarse no se buscan de forma «directa», siempre que se procure que tales males sean los «menores posibles».

El principio de que «el fin no justifica los medios» debe aplicarse cuando el medio constituye en sí mismo ya una acción propia. Esto se conoce por el hecho de que dicho medio tiene ya previamente un motivo para sí mismo, independientemente de una posible ordenación para otro fin.

32. Cfr. F. D'ноОGн, о.c., pp. 241-9. 
La violencia revolucionaria no tiene por qué tener su motivación en sí misma, sino en función de los fines de la revolución, y es en este nivel en el que debe determinarse la «proporcionalidad», y por tanto la legitimidad, del eventual recurso a ella.

Sin embargo, sucede que en la violencia revolucionaria la causación o permisión de los males precede de ordinario a la consecución de los fines revolucionarios. Pero esto no supone que la torne en ilícita, ya que si las motivaciones son «proporcionadas», no se buscarían dichos males de forma «directa», aunque su causación o permisión fuera físicamente inmediata.

Por lo tanto, un mismo medio (la violencia revolucionaria) puede, desde una perspectiva, conducir a la realización de unos valores (la libertad y justicia que pretende la revolución), y a un tiempo, desde otra perspectiva, implicar un mal (privar de la vida humana); si para la puesta en marcha de dichos medios se da un «motivo proporcionado» (como puede serlo la violencia e injusticia estructurales de la situación establecida y los fines de libertad y justicia que persigue la revolución) el mal que conlleva dicho medio queda fuera de la intencionalidad ética. Si no existe dicho «motivo proporcionado» es esta maldad la que determina la intencionalidad, como sucede en el caso del homicidio ${ }^{33}$.

La justificación de la violencia revolucionaria liberadora puede apoyarse en varios fundamentos. Uno de ellos lo constituye la constatación, por medio de análisis y cálculos tácticos y estratégicos, de la injusticia y violencia estructurales de un ordenamiento socio-político «establecido», en el que se perciben como inviables otros procedimientos de transformación radical, o bien porque no se dan (por ejemplo: cauces legales de presión democrática) o bien porque han sido ya agotados sin resultado alguno, o bien porque se.consideran ineficaces (por ejemplo: una resistencia pasiva). En una situación así se concluye la violencia revolucionaria como una «legítima defensa» ${ }^{34}$, cuyos «costos» sociales y humanos no deben superar los sacrificios de la «violencia establecida» del sistema existente. De esta forma la violencia, que en pura abstracción puede representar un «mal», puede resultar aquí y ahora, en su modalidad revolucionaria liberadora, la única forma efectiva de verificar la «bondad» en una situación concreta, en cuanto única defensa socio-históricamente posible frente a un mal mayor que no se puede desterrar de otro modo. Los juicios y consideraciones sobre la violencia que se sitúen en la abstracción de las concreciones situacionales para determinar su legitimidad y eticidad, poco pueden iluminar las conciencias; son los juicios socio-históricos los que sitúan a la violencia revolucionaria en su contexto coyuntural, los que pueden dictaminar su legitimidad o ilicitud éticas a una conciencia que quiere comprometerse con las situaciones concretas.

33. Cfr. P. KNauer, o.c., pp. 271-3.

34. Cfr. M. USEROS, o.c., pp. 198-9. 
Otro de los fundamentos de la violencia revolucionaria se sitúa a nivel de las finalidades que se persiguen con este medio. Para que el recurso a la violencia revolucionaria aparezca en su legitimidad ética estos fines deben necesariamente constituir la superación real y efectiva de la injusticia y violencia estructurales del «sistema establecido» injusto con la consiguiente implantación de la mayor justicia y libertad posibles para la población. Aquí la justificación no depende tanto de la intencionalidad de los revolucionarios cuanto de la funcionalidad objetiva de la revolución y de la disponibilidad de recursos de todo tipo en la sociedad concreta.

Todo lo dicho no quiere significar que se puede justificar cualquier tipo de medios violentos. La moral católica habló siempre de «medios proporcionados» a la agresión que había que repeler, y la moral laica, por boca de $\mathrm{H}$. Marcuse, habla de «medios racionales», cuya efectividad real tiene que encuadrarse dentro del marco de los objetivos fijados por la revolución ${ }^{35}$. En ninguna hipótesis, pues, pueden justificarse modalidades de la violencia que impliquen en sí mismas la negación intrínseca de las finalidades por las que se emprendió la revolución, tales.como la violencia arbitraria, la crueldad, la tortura, el terrorismo indiscriminado, la muerte de inocentes, etc.

\section{UN PUNTO CONFLICTIVO: EL AMOR UNIVERSAL}

Si el amor en cristiano debe abarcar a todos los hombres sin excepción, ¿cómo le va a ser posible al creyente entrar en la lucha contra una determinada clase o categoría de ellos?, ¿puede converger en algún punto una ética sociopolíticamente clasista con el universalismo del amor cristiano?

Comprometerse en la lucha revolucionaria implica la opción por unos hombres contra otros; para alistarse sinceramente con «los de abajo» hay que enfrentarse con «los de arriba». Éste es el angustioso problema que se le plantea a la conciencia del creyente cuando se decide a optar por la causa revolucionaria en una determinada situación, con una opción movilizada por un amor que para no perder su integridad y autenticidad debe abrir sus brazos a todos los hombres.

La conflictividad, el antagonismo y la lucha entre las clases y los sectores socio-políticos, como ya han mostrado la sociología y la politología, es un hecho que se impone fenomenológicamente. Se trata de una imposición sociohistórica que es previa a todo tipo de consideración o valoración ética o religiosa: establecidas determinadas condiciones, componentes y contradicciones sociales (por ejemplo: la apropiación privada de los bienes frente a su producción colectiva) la conflictividad, el antagonismo y la lucha social se imponen como un hecho socio-político, y se constituyen en mecanismos dinámicos de la

35. Cfr. H. MARCuSE, o.c., p. 149. 
evolución socio-histórica. En este contexto pueden constituirse también en una metodología de liberación para las clases y sectores oprimidos, en cuanto que la transformación radical de la estructuración socio-política que ha originado y alimenta una situación así de antagonismo y de conflicitividad puede verse precisada a pasar por el enfrentamiento sistemático y solidario de las clases oprimidas contra las clases dominantes por la resistencia tenaz de estas últimas a dicha transformación. El antagonismo y la lucha entre las clases y sectores sociales expresa un estado o situación de desequilibrio o disfunción social y el método para desbloquearlo y solucionarlo: una imposición sociohistórica y una iniciativa adoptada.

Si el fenómeno se impone como un hecho socio-histórico la alternativa no radica en admitirlo o no, sino en la opción que se adopte. Negar el hecho o desentenderse de él es ya una forma de optar, una manera de favorecer los intereses de las clases y sectores dominantes. Por otro lado, dados estos componentes y componentes actuales de lo social, no se puede amar sinceramente a «los de abajo», sin alistarse con ellos, sin luchar a su lado.

Cuando el Evangelio ordena amar a los enemigos, no afirma que no se tengan o que no haya que enfrentarse a ellos. Hoy por hoy el amor a los que ocupan un lugar socio-político contrapuesto no puede estar al margen de la conflictividad, el antagonismo y la lucha. Estos resultan ser una exigencia de los actuales condicionamientos conflictivos de lo social. $Y$ en un contexto socio-político así el amor cristiano con lo que no puede transigir es con el neutralismo. En palabras de J. Girardi:

«El cristiano debe amar a todos, pero no a todos del mismo modo, al oprimido se le ama defendiéndole y liberándole, al opresor combatiéndole y acusándole. El amor nos exige luchar para liberar a todos los que viven en una condición de pecado objetivo. La liberación de los pobres y de los ricos se realiza al mismo tiempo" ${ }^{36}$.

Según J. Cardonnel para vivir el gran mandamiento nuevo de amar fraternalmente a los poderosos hay que entrar en la lucha que conduce a su desposesión, liberándoles del peso que les impide ser humanos. En este contexto:

«Tenemos que encontrar el gesto inédito, insólito de amar a los enemigos, es decir, a los opresores, a los explotadores. No hay gesto de amor a los enemigos más fuerte que aquel que quebrantará su situación privilegiada de élite para introducirles en la alegría inmensa de una condición común...» ${ }^{37}$.

Sin embargo, no debe olvidarse la constitucional ambigüedad de toda lucha humana. Hay, tanto a nivel psicológico como sociológico, una especie de lógica de la lucha, que tiende a gravitar hacia el odio, la venganza, o al me-

36. J. GiRARDI, Amor cristiano y lucha de clases, (Salamanca 1971), p. 57.

37. J. CARdonnel, $A$ modo de conclusión, en AA.VV.: «La violencia de los pobres», (Barcelona 1968), p. 248. 
nos hacia la hostilidad interna, y que puede desencadenar rivalidades, resentimientos y agresividades desmesuradas, todo lo cual puede propiciar una moral sectaria dispuesta a bendecir cualquier medio.

Subyace, pues, a toda esta cuestión una cierta ambigüedad ética. El amor es lo radicalmente revolucionario. Él es el que dada la peculiaridad de la situación puede verse precisado a no poder prescindir del antagonismo y la lucha, pero es también el que debe juzgar la eticidad de dicha mediación. La distinción entre lucha y odio es teóricamente bastante clara, pero concretamente resulta psicosocialmente muy elástica y resbaladiza. Por ello, incluso en pleno fragor de la lucha revolucionaria, el creyente no debe abandonar o mitigar la capacidad de juzgar, criticar y hasta «contestar» los medios de que se vale. No con el fin de neutralizar la radicalidad de las reivindicaciones revolucionarias, sino para purificarlas, autentificarlas y vigorizarlas. Si la lucha sin amor es contrarrevolucionaria, un amor sin lucha, dada la condición conflictiva de nuestra actual situación, resultaría un «angelismo» enmascarante de la cobardía, el conformismo o el neutralismo.

Particularmente el creyente debe mantenerse crítico para no suponer apriorísticamente verificada siempre la «mala fe» del opresor, desdeñando de esta forma toda la posibilidad de su conversión, y para no buscar la posterior opresión del opresor y la radicalización paroxística de los antagonismos.

La distinción que debe tenerse siempre presente es la que se da entre lucha y odio, ya que no existe un nexo inevitable entre ambos. El creyente jamás podrá alistarse en una revolución que se reduzca a ser pura mediación del odio entre los hombres.

El amor es dinámico, transformador, porque no sólo reconoce y ama al hombre que existe, sino que lo hace creando a un tiempo el «hombre nuevo». Es, pues, un amor militante, comprometido, con un universalismo que implica, hoy por hoy, dada nuestra actual situación, la opción de clase, por la clase que lleve en su seno los intereses y esencias de toda la humanidad, y que, al liberarse a sí misma, libere a todo el mundo, haciendo así efectivo ese universalismo del amor cristiano.

La fraternidad humana que brota del amor y que tiene como último fundamento nuestra común condición de hijos de Dios, tiene que irse construyendo socio-históricamente. Pero la historia y la sociedad están cualificadas por la conflictividad. Una conflictividad dinamizada y caracterizada por un fenómeno central: la división de la humanidad en dominadores y dominados, en opresores y oprimidos, en los «de arriba» y los «de abajo», es decir, en clases, estratos y sectores sociales y políticos antagónicamente enfrentados. Una división que acarrea enfrentamientos, luchas, antagonismos y violencias.

La evolución, el alcance preciso, los matices, las variaciones, la intensidad de estos componentes de lo socio-político-económico son objeto de análisis de las ciencias sociales y políticas. No es un hecho que dependa de eventuales apreciaciones y opciones éticas ni religiosas. 
En opinión de G. Gutiérrez ${ }^{38}$ la exigencia evangélica de la implantación de una sociedad justa y fraterna, dadas estas condiciones objetivas sociales y políticas, no puede situarse al margen de las conflictividades, antagonismos y luchas. Negar o menospreciar esto ya está suponiendo en el fondo tomar partido por los sectores dominantes. La cuestión no radica en admitir o negar algo que se impone por sí mismo sino en la opción consciente y activa que hay que adoptar.

La universalidad del amor cristiano corre el riesgo de degenerar en el abstraccionismo y la complicidad con los estratos dominantes, cuando éstos están injustamente establecidos, si pretende prescindir de la historia y de sus procesos concretos, es decir, de la conflictividad y el antagonismo. Amar a todos los hombres no puede significar, dadas las condiciones objetivas de los actuales procesos socio-históricos, la huida de los enfrentamientos, para intentar buscar una armonía, que, hoy por hoy, aparte de ilusoria, resultaría hipócrita. El amor universal actualmente sólo puede ser el que, al solidarizarse con los oprimidos, se esfuerza a un tiempo y en el mismo proceso liberador por sacar a los opresores de su situación igualmente enajenada por su carácter de dominación, ambición y egoísmo.

Como manifiesta G. Gutiérrez:

«Se ama a los opresores liberándoles de su propia e inhumana situación de tales, liberándoles de ellos mismos. Pero a esto no se llega sino optando resueltamente por los oprimidos, es decir, combatiendo contra la clase opresora. Combatir real y eficazmente, no odiar; en esto consiste el reto, nuevo como el evangelio: amar a los enemigos. Nunca se pensó que esto fuese fácil, pero mientras se trataba de practicar una cierta dulzura de carácter, se predicaba sin dificultad. No se seguía el consejo, pero se le escuchaba sin inquietud. Hoy en el contexto de la lucha de clases, amar a los enemigos supone reconocer y aceptar que se tienen enemigos de clase y que hay que combatirlos. No se trata de no tener enemigos, sino de no excluirlos de nuestro amor. Pero el amor no suprime la calidad de enemigos que poseen los opresores, ni la radicalidad del combate contra ellos. El «amar a los enemigos», lejos de suavizar las tensiones, resulta así cuestionando el sistema y se convierte en una fórmula subversiva" ${ }^{39}$.

Para ser concreto y efectivo el amor universal tiene que encarnarse en el combate por la liberación de los oprimidos y dominados. Las actuales condiciones objetivas de lo sociopolítico imponen al amor una praxis de solidaridad con el hombre expoliado que lucha por lograr una vida de dignidad. El amor no puede hacer abstracción de este hombre, no puede aislarle de la clase y estrato social al que pertenece, sino que para historificarse tiene que adentrarse por los caminos de la solidaridad social, y en consecuencia, de los compo-

38. Cfr. G. Gutiérez, Teología de la liberación, (Salamanca 1972), p. 356.

39. G. Gutiérez, o.c., pp. 357-8. 
nentes de ésta entre los cuales se encuentran la conflictividad y los antagonismos sociales. Inscribirse en ellos es, hoy por hoy, la mediación impuesta por las actuales condiciones de lo socio-político para la concreción social y la historificación de la universalidad del amor cristiano. A primera vista parece una paradoja, pero en realidad no lo es si todo este cuadro se le sitúa en el contexto de un mundo como el nuestro, conformado por una cultura dialéctica, en la que la reconciliación pasa por la superación de los antagonismos por mediación de la conflictividad.

Dentro de todo este contexto global es donde se le puede plantear al creyente el problema de la opción por la violencia revolucionaria. Una opción que depende formalmente del mismo tipo de razonamientos, que en otro lugar se vio a propósito de la opción por la no-violencia:

\section{a) Por motivacaiones ético-religiosas}

No es completamente exacto que la violencia revolucionaria sea una «ultima ratio». Únicamente el amor es la «prima et ultima ratio». Pero su verificación socio-política tiene que pasar por la exigencia de la efectividad. En este nivel la violencia revolucionaria puede aparecer como mediación de esta eficacia para un amor que no quiera evadirse de las imposiciones insoslayables de un contexto preñado de conflictividad.

En su solidaridad con los oprimidos el amor no puede excluir apriorísticamente la eventualidad del recurso a la violencia revolucionaria, ya que ésta puede imponerse en virtud de las peculiaridades de la situación concreta como la única mediación real y efectiva para su liberación. En una situación así el amor, como único imperativo radical y absoluto de la ética cristiana, puede llevar al creyente, para su verificación socio-política, hasta la asumpción de la violencia revolucionaria en el intento de desmantelar la violencia estructural del sistema establecido opresor.

Pero esta opción no puede absolutizarse, so pena de degenerar en el sectarismo ético. Otro tanto sucedería si se pretendiese hacer de la no-violencia un imperativo absoluto (humano o cristiano), con la consiguiente prohibición radical del recurso a la fuerza (incluido el ataque a la vida e integridad física de la persona humana). Estas absolutizaciones, aparte de distanciarse en el caso de la no-violencia de las enseñanzas tradiccionales sobre la legítima defensa, etc., corresponderían a una concepción incorrecta de las ideas correlativas de valores «absolutos» y "relativos» en el ámbito ético. Como afirma J. Fuchs ${ }^{40}$ únicamente el amor y la justicia son valores absolutos (bona moralia) que, en cuanto tales, en ninguna hipótesis pueden ser legítimamente violados. El uso de la fuerza, según Fuchs, implica una acción que viola un valor huma-

40. Cfr. F. Fuchs, Aspectos morales del progreso humano, en AA.VV.: «La teología al encuentro del progreso» (Bilbao 1973), pp. 197-8. 
no relativo y que, por tanto, inflige un «malum physicum». $\mathrm{Ni}$ el mismo hecho de quitar la vida humana constituye en sí mismo un mal absoluto o intrínseco, ya que, de lo contrario, en ninguna hipótesis se podría matar ni dejar morir, lo cual no estaría en consonancia con la tradición moral. Sólo una correcta determinación de las ventajas, una exacta apreciación de los diversos valores y males incluidos en una acción hacen posible establecer una adecuada valoración moral de la misma. En la práctica, la teología moral siempre aplicó este criterio para decidir qué valores relevantes podrían justificar el hecho de dar muerte a la persona humana.

El Sermón de la Montaña no presenta la no-violencia como un imperativo absoluto, sino que consigna solamente como tal el amor y la justicia. En determinadas situaciones, en base al balance de valores y males (relativos) implicados, el amor y la justicia pueden exigir la renuncia a la violencia revolucionaria, pero la disposición para esta renuncia está ya implicada en las exigencias de amor y de justicia, ya que las formas concretas de comportamiento que prescribe el Sermón del monte deben entenderse más bien como «modelos éticos» tal y como pone de manifiesto su estilo hiperbólico de expresión.

La no-violencia encuentra en el evangelio unas resonancias, consonancias y sintonía que no puede pretender el recurso a la violencia, cualquiera que éste sea, pero también el mismo imperativo evangélico radical del amor puede impulsar a recurrir a la violencia revolucionaria. No porque ésta pueda ser jamás percibida o apreciada como un valor, pero sí como la única e impositiva solución socio-política para una situación concreta, en la que, por amor a ellos, se quiere liberar a los oprimidos. Constituye un deber ético para el creyente el hacer todos los posibles, y hasta los imposibles, (pero no se olvide que la política es el «arte de los posibles») para que progresivamente vaya resultando inútil todo recurso a la violencia. Pero, hoy por hoy, éste aún sigue constituyendo una posible mediación de la libertad y de la justicia para determinadas situaciones específicas.

\section{b) En base a los análisis científicos sobre las coyunturas socio-políticas}

La mediación de los análisis técnico-científicos puede determinar la conclusión de que en una situación concreta una revolución mediada por la violencia será capaz de desmantelar la «violencia institucionalizada» del sistema establecido injusto. Entonces la validez ética del recurso a la violencia exige también una cierta garantía de efectividad. Tiene que darse una cierta seguridad sobre la consecución e implantación de un ordenamiento socio-político más justo y libre.

La legitimidad ética de la opción por la violencia revolucionaria implica además que ésta se mueva en el marco de los valores que persigue la revolución, contando siempre con el recurso de los análisis científicos, cuya objetividad y rigurosidad tienen que discernir las posibilidades reales y la oportunidad conyuntural de la implantación en la sociedad de dichos valores. 
Nunca deben desdeñarse los riesgos y las reservas que hay que mantener frente a todo eventual recurso a la violencia revolucionaria, dada la posible potencialidad de los arsenales represivos de que puedan disponer los poderes injustamente establecidos.

En definitiva, toda consideración teórica acerca de la violencia revolucionaria y de la no-violencia alberga sus buenas dosis de relativismo. La decisión por el testimonio no-violento así como la opción por un recurso legítimo a la violencia revolucionaria deben venir siempre mediadas entre otras cosas por los análisis científicos sobre las condiciones objetivas de las situaciones, sobre sus componentes coyunturales, y sobre lo que hic y nunc es éticamente fehaciente en cuanto que viene impuesto táctica y estratégicamente.

Cuando el creyente se ve precisado a optar seria y sinceramente por la violencia revolucionaria, su decisión no puede ser más dolorosa, amarga y torturante, porque se fragua y se verifica entre su amor para con los oprimidos y también para con los opresores. A ambos debe amar con la misma intensidad, pero no de la misma forma. Lo específicamente evangélico no es la noviolencia, sino el amor. Tampoco la violencia revolucionaria, cuando pueda gozar de una posible justificación, es lo antievangélico, sino el absentismo, el conformismo, la negligencia, la opresión, la explotación del hombre por el hombre, la violencia injusta.

\section{ACTITUDES ETICAS A MANTENER EN LA VIOLENCIA REVOLUCIONARIA}

\subsection{Evitar el «espíritu de violencia»}

El «espíritu de violencia», tal y como lo denomina J. M. Díez-Alegría ${ }^{41}$, es absolutamente incompatible con el «espíritu del amor cristiano». Pero no se puede identificar sin más con este "espíritu de violencia» todo recurso a la violencia revolucionaria, incluida la de tipo sangriento, aunque es clara la problematicidad radical para el creyente del recurso a acciones armadas contra otros hombres. Sin embargo, como se ha intentado clarificar líneas atrás, no se puede dictaminar a priori su imposibilidad e inviabilidad éticas y socio-políticas para todo tiempo y circunstancia. Resultaría, en consecuencia, desproporcionada la afirmación incondicional de que el creyente que ejerciera acciones de violencia revolucionaria ha cerrado ya categóricamente su corazón al prójimo, incluido el enemigo. Lo que sí debe afirmarse rotundamente es que todo aquel que recurra a la violencia revolucionaria, porque rehúye todo tipo de amor al prójimo, se ha situado fuera de la órbita del cristianismo.

Hay que reconocer la dificultad y problematicidad concretas de empare-

41. Cfr. J. M. Diez-Alegria, Juicio cristiano de la violencia en relación con el progreso, en AA.VV.: «La Teología al encuentro del progreso» (Bilbao 1973), p. 151. 
jar el amor a la violencia revolucionaria contra una persona humana, a la que se quiere reconocer como prójimo. Pero no es algo apriorísticamente imposible, ya que si la negación del recurso a la violencia revolucionaria de las armas implicase, dada la peculiaridad de la situación concreta, la complicidad, consciente o inconsciente, con otras modalidades de violencia, la «institucionalizada» por ejemplo, que también pueden ser sangrientas, resulta claro cómo puede darse un cerco de violencia ante el que el amor debe adoptar una postura consecuente con él mismo, una opción que tiene que ser liberadora, si bien para ello a veces puede resultar preciso que medie la violencia revolucionaria.

La violencia revolucionaria puede encontrar su legitimación en su carácter de único y viable recurso para terminar con un orden socio-político de «violencia institucionalizada». Sin embargo entonces debe procederse con la máxima economía posible de violencia, y debe preverse razonablemente la posibilidad concreta de arribar, por ese medio, a un ordenamiento socio-político más justo. Una empresa de revolución violenta que embarcase en una aventura desesperada, que concluyese con el fortalecimiento y recrudecimiento de la «violencia establecida» que se pretendía desmantelar, resulta ética y políticamente injustificable.

Esta posible licitud del recurso a la violencia revolucionaria para determinadas situaciones no legitima ya por ello todo tipo de actuaciones. En concreto, son absolutamente injustificables las acciones que traduzcan un "espíritu de violencia»: el odio a las personas, el desprecio a la dignidad de la persona, la pasión de venganza, el sadismo, la tortura, el terrorismo desencadenado e indiscriminado, la injusta opresión del prójimo (sea, o no, enemigo; sea, o no, culpable), la muerte directamente pretendida y perpetrada de inocentes, por más que se la considere un medio estratégicamente eficaz para un fin bueno en sí mismo, etc.

Si bien en el orden de las finalidades el recurso a la acción armada puede quedar justificado ética y políticamente para determinadas situaciones, los problemas más angustiosos se plantean a nivel de la ejecución concreta de la violencia revolucionaria. Es aquí donde, por su dialéctica interna, la violencia revolucionaria corre el riesgo de desembocar en un «espíritu de violencia» que arrastre a acciones inaceptables para una ética cristiana.

La violencia tiende a albergar en su seno una exigencia de continuidad. Propende a engendrar un hábito de simplificación que dificulta enormemente su autocontrol y autolimitación: tiende a simplificar las relaciones con el «otro» en una dinámica de negatividad. Tiende a continuarse y extenderse a sí misma, amplificándose en una escala difícil de frenar.

Esto no significa sin más, como advierte S. Windass ${ }^{42}$, que tenga que darse un vínculo absolutamente necesario entre todo tipo de recurso a la

42. Cfr. S. WINDASS, El cristianismo frente a la violencia, (Madrid 1971), p. 151. 
violencia y el odio o «espíritu de violencia». Pero, con todo, la violencia en sí misma tiende a producir una reacción en cadena, con un incesante incremento de continuidad, hasta propender a desembocar en el odio o «espíritu de violencia».

No es que haya que divorciar el plano de los medios del de los fines para juzgar los medios éticamente al margen de toda consideración de los fines a los que pretenden dirigirse, ya que precisamente en esto radica la razón por la que no se pueden equiparar sin más la violencia de una revolución justa con la violencia de la contrarrevolución que pretende frenarla fortificando la «violencia estructural» contra la que se levantó la revolución.

Pero tampoco se pueden separar los fines de los medios, como si la justicia de los fines pretendidos o las injusticias que se combaten, pudiera legitimar el recurso a todo tipo de medios, sin más límite y medida que los que marcara la eficacia.

Existe una incidencia dialéctica entre los fines y los medios. La permanencia en una dialéctica de justicia a nivel de los fines tiene que revertir en la ejecución de los medios. Quien se dejase aprisionar por la dialéctica del «espíritu de violencia», o quien, obsesionado por la eficacia, llegase a extremos que desencadenasen la dialéctica del "espíritu de violencia», se encontraría en una situación existencial que inevitablemente incidirá en el plano de las finalidades, y de esta forma, en su concreción existencial y social, los impulsos finalísticos pueden terminar por perder su carácter de «dialéctica de justicia» con el que comenzaron a fraguarse. No se trata de adentrarse por los laberintos de la casuística en una cuestión tan compleja como ésta, pero sí que no deben perderse de vista determinados principios éticos irrenunciables, por más márgenes de elasticidad moral que haya que conceder a la peculiaridad de cada situación concreta.

Quien quiere un determinado fin, tiene que querer también los medios que éticamente conducen a él, para mantenerse en un ámbito de moralidad. La bondad ética del medio viene constituida por la inmanencia en él, al menos tendencialmente, del fin justo propuesto. A este respecto manifiesta R. Simón:

«Indudablemente el fin es inmanente a los medios, pero lo es a título de valor y no puede, por lo tanto, contentarse con cualquier medio sino sólo con el medio que esté situado en el dominio del valor. Hay, pues, una especie de inmanencia recíproca entre el fin y el medio y una connotación en el orden del valor entre uno y otro. $Y$ esto es sumamente importante para el problema que nos ocupa, el de la violencia y el de la revolución. Porque si, desde el punto de vista cristiano, la apelación a la revolución violenta puede justificarse como último recurso para desenredar situaciones intolerables, sigue siendo verdad que, en el caso presente, la contradicción entre los medios y el fin hace «violencia» al fin...» ${ }^{43}$.

43. R. Simón, Violencia, Guerra y Paz, en «El Ateísmo contemporáneo», v. 3, (Madrid 1971), p. 554. 
Pero también hay que tener presente que la ineficacia del medio recae sobre su valor. Un medio ineficaz para el fin justo propuesto resulta muy ambiguo axiológicamente. Aquí puede radicar una de las debilidades de la noviolencia para determinadas situaciones, sin que con esto tampoco se pretenda convertir a la eficacia en el criterio principal de valoración ética.

En base a todos estos criterios hay que enfrentarse con el más agudo problema a nivel existencial: ¿es posible en concreto ética y políticamente el recurso a la violencia revolucionaria sangrienta, sin que se pierda el equilibrio dialéctico entre medios y fines, para que no degenere en un «espíritu de violencia», que desencadenase toda una serie de acciones violentas injustas?

Hay que reconocer el peligro cierto y real, por más comprensible que pueda resultar a nivel existencial, de que la violencia revolucionaria sangrienta desemboque en una dialéctica injustificable de violencia o «espíritu de violencia». El posible amor apasionado por la libertad y la justicia no tiene que hacer perder la lucidez por lo que respecta a este.peligro. De aquí que en la noviolencia el creyente encuentre en un principio la opción más connatural con el universo de su fe y con las motivaciones éticas de su compromiso sociopolítico. Sin embargo, a tenor de lo que hasta ahora se ha analizado, no puede negarse la posible legitimidad de una revolución violenta al servicio de la libertad y de la justicia.

El amor es el único imperativo absoluto para el creyente. Este amor debe traducirse en una praxis socio-política eficaz por la implantación de la justicia y la libertad entre los hombres. Esta praxis en determinadas situaciones puede verse precisada a ser mediatizada por la violencia. Es doloroso encararse con lo que realmente no se quiere realizar. La responsabilidad ética del creyente ante lo inhumano de la situación que ha movilizado la acción revolucionaria le exige la militancia en ella, en tanto que el amor incondicional que debe impulsarle le hace sentir una especie de repudio hacia la violencia a la que se ve precisado a recurrir en virtud del estado específico de la situación concreta. Esta especie de esquizofrenia interior y existencial debe impulsarle a salir cuanto antes de este estado de cosas. Asumir la violencia revolucionaria no quiere decir reconocerla como un valor, sino experimentar la contradicción desgarradora, galvanizada por el amor, de tener que recurrir a un medio de esta índole para la implantación de la libertad y de la justicia.

Tiene que tratarse de una violencia revolucionaria movilizada por el amor, nacida, controlada y dominada por el amor, amor al opresor, esclavo de su egoísmo y ambición, y amor al oprimido, deshumanizado por la opresión.

Teóricamente no constituye gran problema tratar el problema de una revolución movida por el amor, ¿pero resulta todo tan simple en la práctica?, ¿cómo lograr que la violencia revolucionaria se autodestruya cuando ya no sea precisa? A este nivel es donde la problematicidad de las cuestiones resulta angustiosa, ¿pero esto tiene que paralizar el compromiso por la libertad y la justicia? 
Pueden darse situaciones, cuando la revolución violenta ya se haya desencadenado en virtud de análisis previos sobre la coyuntura concreta, en las que la alternativa para el creyente no radique ya en la opción por una praxis violenta o no-violenta, sino que la única decisión posible sea la de participar en la revolución violenta ya desencadenada, o la de desentenderse de ella, abogando así, al menos indirectamente, por la opresión e injusticia contra las que se ha levantado la revolución. Entonces la única alternativa está en optar o bien por la violencia de los opresores o bien por la de los oprimidos. Pretender abstenerse de la violencia en un contexto así puede suponer el favorecer la violencia ya «establecida».

Por otro lado el realismo, del que no tiene que desentenderse el planteamiento ético de cualquier problema socio-político, obliga a reconocer que las posibilidades de la no-violencia son muy problemáticas para determinadas situaciones, en las que un profetismo anárquico e individualista podría resultar contraproducente, y la no-violencia, por querer «conservar las manos limpias», en el fondo podría estar haciendo el juego a la «violencia institucionalizada» de un ordenamiento socio-político injusto, ya que la no-violencia, por moverse de ordinario en círculos minoritarios, todavía no presenta la suficiente eficacia como para constituir un medio de envergadura suficiente como para enfrentarse con posibilidades de éxito al enorme aparato opresivo-represivo de que suelen disponer en la actualidad los sistemas injustos establecidos. El futuro de la no-violencia depende de su capacidad para movilizar a grandes masas, a pueblos enteros, y esto resulta muy problemático cuando los controles represivos son gigantescos y no existe la cobertura de unas mínimas libertades públicas ${ }^{44}$.

Pero también es cierto que la ética de la violencia revolucionaria es una «ética de la angustia». Es la situación en que la conciencia se enfrenta a la perplejidad de tener que optar entre dos o más males. La opción por la violencia revolucionara es angustiosa para el creyente. Pero se dan situaciones en que resulta imposible huir del cerco de la violencia: o se opta por la violencia de los oprimidos, o se favorece, con una pretendida abstención la de los poderes opresores, aunque esto no se pueda desear directamente.

\subsection{La exigencia cristiana de la reconciliación en el corazón mismo de la re- volución}

Quizá sea la reconciliación la praxis que más especifique la identidad del creyente en la revolución. El gesto que debe definir al cristiano es el de la fraternidad, el de la reconciliación, el de la aceptación del enemigo en el perdón, o al menos el de mantener viva la tensión por estas actitudes mientras la situación concreta no permita aún su efectiva verificación.

44. Cfr. J. M. Diez-Alegria, o.c., p. 244. 
La oferta de la reconciliación, en medio de la refriega de la lucha revolucionaria, es imprescindible para mantener la identidad socio-política creyente. El amor revolucionario tiene que hacer todo lo posible por sanar las heridas y por unir las roturas que ocasionen los enfrentamientos y las luchas. Negarse desde un principio a tender la mano al adversario supondría incidir en la dialéctica o «espíritu de violencia», incompatible con el amor cristiano.

$\mathrm{El}$ amor revolucionario tiene que tender a la reconciliación universal y a la supresión de los antagonismos. Un amor auténticamente revolucionario tiene que ser reconciliador. No puede considerarse a priori irredentos a ninguna sociedad, ni a ninguna clase social ni a ninguna persona. Todos en principio pueden ser rescatados de su desamor y ganados para la reconciliación fraterna, antes de tener que plantearse el eventual recurso a la violencia revolucionaria en el caso de que se mostrara manifiesta su cerrazón a la conversión.

La reconciliación exige una capacidad de iniciativa y de creatividad generosas para trazar puentes de unidad y de concordia, gestos de fraternidad, incluso cuando los análisis sobre la situación socio-política concreta hubieran ya determinado la insoslayabilidad del recurso a la violencia revolucionaria.

Pero se desvirtúa el auténtico sentido de la reconciliación cuando se la confunde con una política de apaciguamiento de los antagonismos originados por los desequilibrios e injusticias socio-políticas, o cuando se la utiliza para "tranquilizar» a los oprimidos, o cuando se la adopta como tapadera para evitar la toma radical de postura frente a situaciones intolerables, ya que en un mundo todavía dividido el apaciguamiento no constituye un medio de reconciliación, sino una forma soterrada de prorrogar la dominación y opresión de unos hombres sobre otros:

Según J. Moltmann,

«Demostrar y practicar la liberación humana por la reconciliación de Dios significa mantener la llama de la esperanza en medio del odio que brota de toda reacción y revolución...» ${ }^{45}$.

La reconciliación tiene que verificarse en medio de una praxis liberadora. Implica de esta forma una dinámica de transformación. Toda transformación social que no conlleve la exigencia de la reconciliación corre el peligro de degenerar en el terrorismo y la dictadura. Es por la reconciliación por el punto por el que puede romperse la espiral o el círculo vicioso de la violencia. El amor reconciliador confía en la capacidad de conversión del enemigo y desconfía de la absolutización de las propias posiciones, posturas y opciones. El creyente debe luchar contra la injusticia y la opresión, pero a un tiempo debe ser inmune a la seducción del odio y del «espíritu de violencia».

La reconciliación implica el retorno a la armonía e igualdad entre las cla-

45. J. Moltmann, Dios reconcilia y hace libres, en «Selecciones de Teología», 10, n. 38, 1971 , p. 216. 
ses sociales y las personas, que antes estuvieron unidas, o el esfuerzo por armonizar en un futuro a los que ahora se mueven en posiciones de desigualdad. Pero para que el oprimido se reconcilie con el opresor es preciso que éste abandone su posición de tal.

Toda auténtica revolucion debe ser reconciliadora, al menos tendencialmente. Pero es en el transcurso del proceso y de las vicisitudes revolucionarias donde se plantean los problemas más agudos. Pretender en medio de fragor revolucionario una reconciliación absoluta podría suponer el escamotear la injusticia que se pretende combatir, establecer un maridaje entre la reconciliación con la opresión y la injusticia. Pero negar o abortar el grado de reconciliación posible en cada momento y situación supondría la absolutización de la violencia, la lucha y el antagonismo.

La violencia revolucionaria se mueve en una permanete ambigüedad. Intenta mediar en la reconstrucción de una humanidad reconciliada consigo misma, pero por medio del enfrentamiento y de la lucha. Por ello entre sus cálculos tiene que entrar el prevenir todas aquellas eventualidades que pudieran comprometer irremediablemente el futuro de reconciliación. Ésta es la razón por la que el creyente no puede odiar a su adversario, aunque tenga un arma en sus manos. Sin embargo, hay que reconocer que una revolución violenta en la que no se dé la más mínima concesión al odio es muy problemática, aunque no apriorísticamente imposible. Para ello el creyente tiene que estar siempre abierto y dispuesto al perdón y a la reconciliación con el enemigo, aunque para ello tenga que aceptar determinados «compromisos», una vez que se haya asegurado lo esencial de la justicia y de la libertad que se pretende.

\subsection{Discernimiento en el proceso revolucionario}

Cuando una corriente revolucionaria ha penetrado profundamente en la trama de un contexto socio-histórico, suele terminar por madurar y por exigir una ruptura radical. Y puede suceder que no logre imponerse de forma puramente pacífica en virtud de las resistencias de lo «establecido». Por ello puede no depender de las fuerzas revolucionarias la realización pacífica del cambio socio-político, sino de la resistencia o flexibilidad de lo «establecido» injustamente ante la transformación que se pretende.

Las revoluciones de ordinario no son puramente ciegas. Tienen sus propios dinamismos históricos y socio-políticos, pero entre sus componentes cuenta también la responsabilidad humana. Tanto en la fase previa a la explosión revolucionaria, como en los momentos de verificación y conclusión, la voluntad humana tiene su parte en el desarrollo de los acontecimientos ${ }^{46}$.

La revolución persigue la implantación de un nuevo poder. El pronóstico de K. Marx de que la revolución social superaría toda dominación y toda for-

46. Cfr. J. Comblin, Teología de la revolución, (Bilbao 1973), p. 346. 
ma de poder comparables al papel que siempre desempeñó el Estado no parece todavía posible en un futuro más o menos previsible. La experiencia de las mismas revoluciones socialistas y comunistas verificadas hasta el presente así lo sugiere por el momento. Por lo tanto un nuevo poder tiene que hacerse cargo de las transformaciones programadas por la revolución. Esta necesidad del poder estatal es uno de los síntomas de los límites de toda revolución.

Ésta es la razón por la que ninguna causa revolucionaria puede exigir del creyente una adhesión sin reservas, ya que la distancia que suele establecerse entre el programa revolucionario inicial y el tal o cual Estado revolucionario que lo toma a su cargo impone en el creyente una capacidad de crítica y de reservas en su adhesión a la revolución.

No se puede hacer la revolución cuando se quiere. La falaz ilusión de muchos movimientos revolucionarios es pensar que se pueden forzar los procesos socio-históricos a golpes de voluntad. Las únicas revoluciones que pueden consumarse son las que ya se han venido largamente gestando y que han alcanzado un punto de madurez por contar con la concurrencia de un conjunto de factores favorables, tanto de orden objetivo como subjetivo. Los revolucionarios más geniales fueron unos oportunistas sagaces, que acertaron a descubrir, interpretar, manejar y combinar las fuerzas y factores que ya estaban movilizados. Por ello los planteamientos éticos tienen que moverse en el marco de un dilema: o «esta» revolución o ninguna. El creyente, como los demás, no puede esperar a que aparezca en el horizonte una revolución irreprochable y carente de riesgos para prestarle su adhesión, ya que la que solamente aparecerá será la que en aquel momento sea posible.

Ante el dilema deben sopesarse los pros y los contras: ¿merece esta revolución, que es la única ahora posible, los costos sociales y humanos que demanda? Si los costos son de envergadura, hay que tener en cuenta que una ocasión desdeñada no volverá de ordinario a presentarse ya en la historia.

También puede suceder que la revolución en concreto no pueda hacerse con los compañeros de lucha que el creyente quisiera. Por ello el creyente deberá hacer sus cálculos y previsiones acerca de quién o quiénes heredarán el poder político que la revolución dejará vacante para juzgar de la oportunidad y conveniencia de prestarles su apoyo para hacerse con él.

El recurso a un medio como la violencia revolucionaria sólo puede justificarse cuando se parte de una situación social y éticamente intolerable y se pretende arribar a un término de mayor justificia y libertad. Si el movimiento revolucionario no desemboca en un cambio fundamental de la situación, la revolución habrá pagado inútilmente un alto costo socio-humano, y se habrá sentado el germen de una nueva revolución o posiblemente de una contrarrevolución aún más represiva que el estado social anterior. Se aquí la importacia de fijar con claridad los objetivos finales y de no dejar que se disuelvan entre el polvo y los escombros del régimen derrocado. Constituye una fuerte tentación limitarse al desmantelamiento del régimen oprobioso, cuando en realidad la etapa reconstructiva es la fundamental de la revolución; la lucha 
contra el régimen que se pretende destruir constituye el preámbulo para emprender la edificación de un ordenamiento socio-político más justo ${ }^{47}$.

El fervor revolucionario puede oscurecer fácilmente la visión clara de las cosas, y su carga pasional puede llegar a desequilibrar el sentido de la proporcionalidad. Por ello el combate revolucionario exige una especie de ascesis, de dominio sobre las zonas más inflamables del psiquismo humano para que el proceso revolucionario no se descauce, para que la revolución no vaya acumulando un saldo negativo que cada vez vaya comprometiendo más los principios y finalidades que la inspiran. Es necesario ir atemperando continuamente las tendencias a los extremismos, dado que la misma dinámica de la lucha suele inflamar los ánimos induciéndoles al unilateralismo.

La revolución encuentra su justificación en cuanto mediación para desmantelar una injusticia y desequilibrios sociales sumamente más graves a los males que pueda acarrear la explosión revolucionaria; en el fondo constituye una forma de repeler, en una situación determinada, una agresión camuflada en la «legalidad». Es solamente el tránsito hacia una nueva sociedad. Desvirtuar este sentido supone despojarla de su justificación.

Durante el período revolucionario a veces se impone la restricción de determinadas libertades y garantías constitucionales. El reordenamiento sociopolítico puede necesitar que el nuevo poder implantado invada zonas que en una situación normal no le competerían; pero la perpetuación de esta situación supondría el acercamiento o la inscripción en la dictadura o el paternalismo. Por ello el creyente tiene que mantenerse lúcido y crítico frente a toda exaltación de la violencia revolucionaria y de las medidas dictatoriales, que puede producir la intensidad con que se vive la lucha revolucionaria o la necesidad del poder revolucionario de gobernar durante un determinado tiempo sin controles ni oposición ${ }^{48}$.

$¿$ Todo lo dicho quiere decir que el creyente no puede alistarse en un proceso revolucionario sin reticencias, vacilaciones, reservas y ambigüedades?

No se precisa la irreprochabilidad de una causa revolucionaria en todos sus aspectos para entregarse a ella con plenitud de compromiso por parte del creyente. Pero hay que reconocer que hasta el presente las grandes revoluciones no estuvieron exentas de su correspondiente dosis de fanatismo. Quizá no siempre a nivel de los dirigentes, pero sí a nivel de los agentes principales (jacobinos, comunistas, etc.). En este punto es donde el creyente puede individuar su identidad socio-política, poniéndose en guardia, en virtud de su «reserva escatológica», frente a todo intento de sacralizar o absolutizar los empeños revolucionarios, sean del tipo que sean.

A veces se quiere encontrar en la revolución el acto total y absoluto de la

47. Cfr. G. ClaPS, El cristiano frente a la revolución violenta, en «Mensaje», n. 115, 1962, p. 723 .

48. Cfr. G. ClaPs, o.c., p. 724. 
libertad y de la justicia. Sin embargo un acto de este tipo no existe. Solamente se da una cadena de actos limitados, tanto por lo que respecta a sus pretensiones como a su sentido, en el tiempo y en el espacio. Pero de esta limitación no hay que concluir su inutilidad, sino la provisionalidad, incertidumbre y precariedad de todo empeño humano, para saber optar, entre todo lo que se presenta como posible, lo mejor para cada momento y situación concretos. Aquí radica uno de los problemas de la opción del creyente. Ninguna acción o programa puede abarcar completamente todo lo «humano», pero no queda más remedio que optar por lo mejor posible en cada coyuntura concreta.

Toda revolución, como en general sucede con toda praxis socio-política, conlleva una cierta complicidad con la injusticia y el desorden, aunque pretenda el mayor grado posible de justicia y libertad. ¿Pero dónde situar los límites de esta complicidad más allá de los cuales comenzaría lo éticamente intolerable? Ya es bueno que este problema se plantee, ya que de ordinario tanto los revolucionarios como por su parte los contrarrevolucionarios, pretenden gozar de una «buena conciencia», cada uno desde su perspectiva. Por ello el creyente tiene que mostrarse autocrítico frente a la tentación del egocentrismo presuntuoso; frente al riesgo de implantar un nuevo dominio del hombre sobre el hombre, el creyente tiene que aportar la incesante impugnación de toda forma de dominación; frente a la tentación de justificar cualquier tipo de medios en aras de los fines, tiene que mostrarse sumamente escrupuloso en el posible recurso a la violencia o a la fuerza; frente a la tentación de estigmatizar al adversario como una personificación del mal, tiene que tender sus manos al enemigo en una oferta continua de reconciliación.

Una de las más evidentes tensiones es la que se plantea entre el programa revolucionario y las estrategias concretas que exige la conquista del poder político. Existe el riesgo de enfatizar estas estrategias, haciendo disminuir por otro lado la fuerza del programa revolucionario al que deben mediatizar. Una vez conquistado el poder político, éste puede hipertrofiarse en la obsesión por su consolidación, con el riesgo de mantener en la marginación al programa revolucionario original y con él a la revolución misma. Aquí puede radicar una de las contribuciones del creyente a la revolución, por su reserva frente a toda forma de poder: la defensa constante de la integridad del programa original.

\section{EL AMOR DE LA NO-VIOLENCIA Y LA VIOLENCIA REVOLUCIONARIA DEL AMOR}

Lo que aquí se plantea es una alternativa de fondo: ¿el amor de la noviolencia o la violencia revolucionaria del amor por los oprimidos? Sin embargo, de esta forma no se plantea correctamente la cuestión, ya que la respuesta, a tenor de lo que hasta ahora se ha analizado, tiene que configurarse de una forma copulativa: tanto el amor de la no-violencia como la violencia revolucionaria del amor por los oprimidos constituyen dos actitudes éticas y dos recursos tácticos para el creyente. 
La no-violencia encuentra unas claras resonancias y una sintonía diáfana con las instancias evangélicas: en un mundo como el nuestro, preñado de violencias, los no-violentos están vocacionados a testimoniar uno de los profetismos y actitudes que más necesita nuestra época. Pero con esto no se está negando toda posible eticidad a la violencia revolucionaria, cuando constituye la única mediación posible para arribar a condiciones socio-políticas más justas y libres en una determinada situación.

En un contexto socio-político concreto la no-violencia puede constituir la única opción ética válida por ser la estratégicamente más eficaz. En otro, la violencia revolucionaria puede imponerse como la única mediación estratégicamente eficaz de la libertad y de la justicia.

Unos creyentes pueden sentirse llamados al testimonio profético de no responder jamás con violencia sangrienta a la agresión de los opresores: Otros pueden verse convocados a ser testigos de la fuerza de la justicia y de la libertad contra las estructuras y personas opresoras.

Lo éticamente decisivo es que tanto una opción como la otra tengan en el amor su origen fontal para convertirse en su mediación vital y concreta. El imperativo del amor es tan absoluto para el creyente, que no puede reservar ninguna zona de su existencia al desamor, el odio, la venganza, el «espíritu de violencia», la negligencia, la indiferencia y el neutralismo. De esta forma quien opte por la no-violencia tiene que ser porque el amor le impide existencialmente asumir cualquier praxis de violencia sangrienta, aparte las pertinentes consideraciones y análisis estratégico-tácticos. Igualmente quien opte por la violencia revolucionaria, para que pueda ser validada éticamente, tiene que venir urgida por un amor por los oprimidos que le arrastre a asumir una realidad como la violencia revolucionaria, en cuanto que en la situación concreta constituye la única forma de liberar al oprimido y de rescatar de su situación al opresor. Lo que da coherencia ética a la actitud del creyente violento, lo que traba moralmente los hechos de su praxis revolucionaria, es la lógica de una actitud de amor y de entrega a la causa de la libertad y de la justicia, que puede terminar en el sacrificio de la propia vida.

Es clara la calidad ética del creyente que hace la oferta de su vida al renunciar a todo recurso a la violencia sangrienta, pero también puese existir una gran densidad ética en el creyente que, por amor a sus hermanos oprimidos, recurre a la violencia revolucionaria en una búsqueda honesta de la libertad y de la justicia, cuando no existe otra forma de implantarlas en una situación determinada.

La violencia constituye uno de los componentes de nuestro mundo. Entre sus múltiples manifestaciones se encuentra la "violencia estructural», perpetrada contra las víctimas de sistemas socio-políticos injustos y opresores. En esta situación la violencia revolucionaria puede resultar el «mal menor» y la respuesta ético-política a la violencia que condena estructuralmente a masas enteras a la miseria, la desesperación, la opresión e incluso la muerte. 
No puede, pues, afirmarse que la única opción posible para el creyente sea la de la no-violencia. Pero sí que el recurso a la violencia revolucionaria exige una exacta apreciación de los fines que pretende mediatizar, un reconocimiento de los riesgos que le son inherentes, de la problematicidad de su control una vez puesta en rodaje, y una total escrupulosidad ética en su ejecución.

Como afirma J. M. González-Ruiz hay que desacralizar y desatanizar tanto el recurso a la violencia liberadora como la opción por la no-violencia ${ }^{49}$.

Los opresores y explotadores satanizan los métodos violentos creando fuertes «reflejos condicionados» en las mentes de los oprimidos, para que reaccionen frente a la violencia liberadora, como si se tratara de una amenaza para la «seguridad y el orden» de su existencia, garantizados por el statu quo, que en realidad los está oprimiendo y explotando. También los oprimidos corren el peligro de sacralizar los métodos revolucionarios violentos, absolutizándolos. Por ello el creyente tiene que desatanizar y desacralizar la violencia revolucionaria a puro medio funcional y relativo.

Pero también existe el peligro de sacralizar y satanizar los métodos noviolentos, y por ello el creyente tiene que reducirlos a la categoría de medios funcionales y relativos.

Las «personas de orden» tienden a diferenciar demasiado tajantemente la violencia que se ejerce desde el Poder (puede que injustamente), un Poder que de ordinario se constituyó por medio de la violencia, pero que se ha ido legitimando con el transcurso del tiempo, de la violencia que se ejerce desde la Oposición (puede que justamente). La primera, en cuanto que mantiene y apuntala el «orden establecido», tiende a ser considerada, por ese mero hecho y sin más disquisiciones éticas y socio-políticas, como legitimada; la segunda tiende a ser considerada como «subversiva» (en el sentido negativo) y, por tanto, como ilegítima.

Resulta que la mayoría de los regímenes políticos han sido introducidos por mediación de la violencia (de una guerra de independencia, de una guerra civil, de una revolución, etc.) y suele ser el transcurso del tiempo el encargado de legitimar aquella violencia fundacional. Por esta razón la ética tiene que juzgar la licitud de un régimen socio-político, violentamente implantado, en virtud de sus posteriores resultados de justicia y libertad. Son bien conocidos, por ejemplo, las violencias y horrores de la Revolución Francesa, y sin embargo hoy los hombres descubrimos en ella un progreso ético, histórico y sociopolítico para la humanidad, que la justifica y legitima, a pesar de su violencia constituyente.

49. Cfr. J. M. González-Ruiz, Dios está en la base, (Barcelona 2. 1973), pp. 197-8. 


\section{CONCLUSIÓN: EL AMOR INCONDICIONALMENTE Y HASTA EL FIN}

El amor constituye un imperativo absoluto para el creyente. Pero este imperativo evangélico ha adquirido hoy nuevas dimensiones, frentes y perspectivas. La comprensión y vivencia actuales de las instancias evangélicas vienen condicionadas y mediatizadas por la marcha de lo socio-histórico, sin que esto suponga su reducción a un craso relativismo, sino la clara aceptación de su inscripción en la existencia humana concreta.

El creyente no puede gozar de sosiego mientras existan hombres que padezcan opresión. El amor no puede degenerar en algo etéreo o en un sentimentalismo estéril, sino que debe unirse a la lucha de los que combaten por su liberación, aunque ésta pueda venir mediatizada por la violencia revolucionaria. Igualmente hay que amar también a los que mantienen o propician la injusticia y la opresión, y para ello quizá la forma sea, cuando se niegan a la conversión voluntaria, la de enfrentarse a ellos para hacerlos abandonar su inhumana situación.

El mandato del amor es, pues, en el fondo el imperativo de transformar activamente toda situación en la que el hombre tenga que ser liberado de alguna alienación.

Éste es el reto para todo creyente comprometido en la lucha revolucionaria: combatir contra la injusticia y la opresión, incluso violentamente cuando la peculiaridad de la situación así lo exija, pero jamás con odio o con «espíritu de violencia», y siempre con la oferta constante de la reconciliación. En esto estriba el quid de la viabilidad ética y cristiana de la opción por la violencia revolucionaria.

Hoy el amor sólo puede cumplirse en su integridad si se adentra por los vericuetos de lo «público». Las actuales «teologías políticas» están denunciando las insuficiencias de los proyectos y tentativas de un amor que se reduzca a lo interpersonal y a lo íntimo en el contexto de una sociedad tan marcada por las divisiones y antagonismos como la nuestra ${ }^{50}$. El amor en estas teologías ya no tiene como destino prioritario el «tú» próximo, sino las colectividades socio-humanas: su verificación se lleva a cabo no tanto en la relación "corta» del "yo» con el «tú», sino en la relación «larga» para con las clases, los grupos y los pueblos, una relación que viene mediada estructuralmente y que se tramita en claves de justicia y de libertad ${ }^{51}$.

Este planteamiento político del amor evangélico constriñe a pasar de una praxis terapeútica de restañar heridas a otra de carácter preventivo para cortar las raíces últimas de los males que aquejan a la sociedad, a la política y a la economía.

50. Cfr. A. Fierro, El crepúsculo y la perseverancia, (Salamanca 1973), p. 176.

51. Cfr. F. Bıт, Teología de las realidades politicas, (Salamanca 1974), p. 176. 
De esta forma puede comprenderse la propuesta de A. Fierro:

«Cuando se apresta a cumplir un proyecto social y político, el amor evangélico, en cuanto voluntad de humanización, aparece como propelente revolucionario de primer orden» ${ }^{52}$.

Es en este contexto en el que la ética cristiana de la violencia revolucionaria puede aparecer como variante o como mediatización de la teología del amor socio-políticamente revolucionario. En el horizonte del amor cristiano la violencia revolucionaria se presenta, en palabras de R. Alves, como «opus alienum Dei», como expresión no íntegramente pura del amor, pero sí como «concesión que hace el amor a las contingencias e imperfecciones de la vida histórica» ${ }^{53}$.

A. Fierro, por su parte, manifiesta:

«En nuestra sociedad el conflicto de clases es una lucha esencial. De esta manera la caridad política llega a asumir la lucha de clases. Esto significa que el amor cristiano puede hacer suyo el análisis marxista de la realidad social y también el modelo operatorio de la praxis marxista; pero al mismo tiempo que rescata del desamor a la lucha de clases y la transforma en instrumento paradójico del amor. Precisamente una de las aportaciones de los cristianos a la lucha para la liberación de los oprimidos está en hacer de ella un acto de amor a la humanidad, a los hombres concretos, a los grupos humanos» ${ }^{54}$.

J. Cardonnel está persuadido de que, dadas las condiciones de nuestras sociedades, la lucha tiene que ser uno de los componentes o mediaciones del amor:

«No hay gesto de amor más fuerte a los enemigos que aquel que quebrantará su situación privilegiada de élite para introducirles en la alegría inmensa de una condición común».

«Para vivir el gran mandamiento nuevo de amar fraternalmente a los latifundistas sudamericanos tengo que entrar en la lucha que conduce a su desposesión» ${ }^{55}$.

J. Girardi es consciene de la paradoja que supone para el amor el verse precisado a recurrir a la violencia revolucionaria, pero lo considera insoslayable para determinadas situaciones:

«Ciertamente es terrible tener que matar por amor pero puede ser necesario» ${ }^{56}$.

52. A. Fierro, La fe contra el sistema, (Estella 1972), pp. 52-3; Cfr. también J. B. METZ, El problema de una «teología política», en «Concilium», n. 36, 1968, p. 398; G. VACCARI, o.c., p. 328.

53. R. Alves, Cristianismo, ¿opio o liberación?, (Salamanca 1973), p. 275.

54. A. Fierro, El evangelio beligerante, (Estella 1975), p. 276.

55. J. CARDONnEl, Amor creador y revolución, en AA.VV.: «La violencia de los pobres» (Barcelona 1968), p. 248.

56. J. GiRARDI, o.c., p. 71. 
«...si de hecho la lucha sin amor se convierte en estéril y contrarrevolucionaria, el amor sin lucha de clases es ilusorio y enmascara el egoísmo y la perezai) ${ }^{57}$.

Todas estas consideraciones pueden ser contestadas desde la perspectiva de poder albergar un partidismo desintegrador de la universalidad inherente a la identidad del amor cristiano. J. Guichard se hace cargo de esta eventual objeción y responde de la forma siguiente:

«En contra de todas las apariencias, la estrategia revolucionaria, la lucha de clases abre una perspectiva de universalidad mientras que la estrategia reformista, de colaboración de clases, encierra dentro una lógica de división» ${ }^{58}$.

Lo que tiene que estar fuera de discusión es que el creyente, para no perder su identidad de tal, nunca puede excusarse de amar, no sólo al prójimo oprimido que lucha por su liberación, incluso con las armas en la mano, sino también al enemigo que ejerce la opresión, aunque tenga que enfrentarse a él.

La violencia revolucionaria tiene que buscar en todo momento su máxima «economía» posible. Si es que debe producirse por la obstinación y amurallamiento de los controles opresivos-represivos del sistema injustamente establecido y por las imposiciones socio-históricas de las situaciones concretas, debe estar humanizada al máximo, movilizada siempre por el amor y jamás por el odio.

P. Freire afirma que

«...el contrario del amor no es, como muchas veces se piensa, el odio, sino el miedo de amar que es el miedo de ser libre. La mayor, la única prueba de amor verdadero que los oprimidos pueden dar a los opresores es retirarles, radicalmente, las condiciones objetivas que les dan el poder de oprimir, y no acomodarse, masoquísticamente, a la opresión. Solamente así, los que oprimen pueden humanizarse. Y esta tarea amorosa, que es política, revolucionaria, pertenece a los oprimidos. Los opresores, en cuanto clase que oprime, jamás liberan, así como jamás se liberan. Sólo la debilidad de los oprimidos es lo suficientemente fuerte para hacerlo».

«...Para mí, violento es el acto con que unos hombres o clases impiden a otros ser. Ahí está el desamor. Por el contrario, amoroso es el acto que busca anular esta prohibición. La violencia de los oprimidos no es violencia, sino respuesta legítima; es afirmación del ser que ya no teme la libertad y que sabe que ésta no es un presente, sino una conquista»" ${ }^{59}$.

Tomás Olivar PONCELA

57. Ibidem, p. 59.

58. J. GUICHARD, Iglesia, lucha de clases y estrategias politicas, (Salamanca 1973), p. 117.

59. P. Freire, Tercer Mundo y Teología. Carta a un joven teólogo, en «Selecciones de Teología», 13, n. 50, 1974, p. 180. 